\title{
Revision of the actinopterygian genus Mimipiscis (= Mimia) from the Upper Devonian Gogo Formation of Western Australia and the interrelationships of the early Actinopterygii
}

\author{
Brian Choo
}

Key Laboratory of Evolutionary Systematics of Vertebrates, Institute of Vertebrate Paleontology and Paleoanthropology, Chinese Academy of Sciences, PO Box 643, Beijing 100044, China

Research School of Earth Sciences, The Australian National University, Canberra, ACT 0200, Australia

Museum Victoria, Melbourne, Victoria 3001, Australia

Email: ozraptor4@hotmail.com

\begin{abstract}
The Devonian actinopterygian Mimia Gardiner \& Bartram (1977) of the Upper Devonian (Frasnian) Gogo Formation of Western Australia, one of the most completely known of all Palaeozoic ray-finned fishes, is renamed Mimipiscis nom. nov. due to preoccupation of the former genus by the butterfly Mimia Evans (1953). Recently acquired data, including the description of newly prepared fossil material, has revealed the presence of a second species in this formerly monotypic genus, as well as previously unreported features of the tail, parasphenoid and ontogenetic variability of type species, Mimipiscis toombsi (Gardiner \& Bartram 1977). The second form, Mimipiscis bartrami sp. nov., differs from the contemporary $M$. toombsi in details of the body shape, squamation, snout, suboperculum and parasphenoid. Phylogenetic analyses recover Mimipiscis and Gogosardina as sister genera within a monophyletic Mimiidae, a clade restricted to the Late Devonian of Western Australia.
\end{abstract}

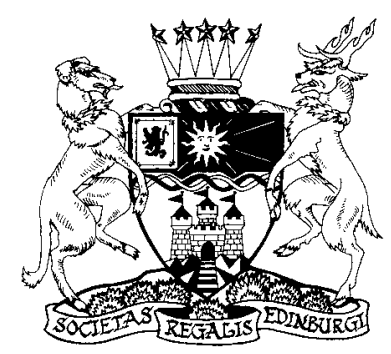

KEY WORDS: Anatomy, fossil, Frasnian, Gondwana, ray-finned fish

The fossil ichthyofauna of the Gogo Formation of Western Australia includes the most completely known Devonian actinopterygians (Gardiner 1984; Long 2006). Based on material collected in the 1960s and transported to the Natural History Museum, London, two taxa, Moythomasia durgaringa Gardiner \& Bartram, 1977 and Mimia toombsi Gardiner \& Bartram, 1977, were given preliminary descriptions based primarily on neurocranial anatomy (Gardiner \& Bartram 1977). Detailed anatomical descriptions were subsequently presented by Gardiner (1984). Moythomasia durgaringa was assigned to a widespread genus with representatives in the Late Devonian of Latvia (Gross 1950), Germany (Jessen 1968) and the United States (Gardiner 1963) whereas Mimia toombsi represented a new genus, endemic to the Gogo Formation. The squamation of both taxa was described in detail by Trinajstic (1999a, b), with isolated scales from both forms recorded from the Gneudna Formation of the Upper Devonian of the Southern Carnarvon Basin, Western Australia. With such excellent fossil preservation, at least one of the Gogo actinopterygians have been present in most recent phylogenetic analyses of early ray-finned fish and, more generally, of early osteichthyans. (Long 1988; Gardiner \& Schaeffer 1989; Schultze 1992; Coates 1999; Schultze \& Cumbaa 2001; Cloutier \& Arratia 2004; Gardiner et al. 2005; Friedman \& Blom 2006; Long et al. 2008; Swartz 2009).

The nomen Mimia was originally erected by Evans (1953) as a genus of Mexican hesperiid butterfly. This invalidates the use of the nomen Mimia (Gardiner \& Bartram 1977) as a genus of fossil fish. The name Mimipiscis nom. nov. is, therefore, substituted for the Gogo actinopterygian.
The presence of additional taxa of Gogo actinoptergians was revealed after preparation of material in the collections of Museum Victoria and the Western Australian Museum. The recent description of Gogosardina coatesi Choo, Long \& Trinajstic, 2009 represents the first new taxon of Gogo ray-finned fish to be named in over thirty years. During the 2005 Museum Victoria expedition to the Gogo Formation, a nearly complete fossil specimen was discovered (WAM 08.9.1) that closely resembled Mimipiscis toombsi, but with key differences in squamation and body shape. This prompted a re-examination of specimens within Australian and British collections, after which it became apparent that material assigned to $M$. toombsi contained two distinct congeneric species (as well as additional examples of Gogosardina). In addition to a revised description and additional anatomical observations of the type species, the second form of Mimipiscis is detailed herein.

\section{Geological setting}

The Gogo Formation, of the Canning Basin (Fig. 1), preserves the deep inter-reef basinal facies of a Late Devonian (Early Frasnian) barrier reef complex (Teichert 1949; Playford \& Lowry 1966; Druce 1975; Towner \& Gibson 1983). Unweathered sections consist of sequences of siltstone and thin beds of limestone, the latter containing round bedded nodules, ranging in size from around $2.5 \mathrm{~cm}$ to $36 \mathrm{~cm}$ in diameter. These concretions are composed of silty micritic limestone and are often found to have developed around a fossil fish or invertebrate. The nodules are resistant to weathering and fossil collecting occurs in extensive surface aggregates on the valley 


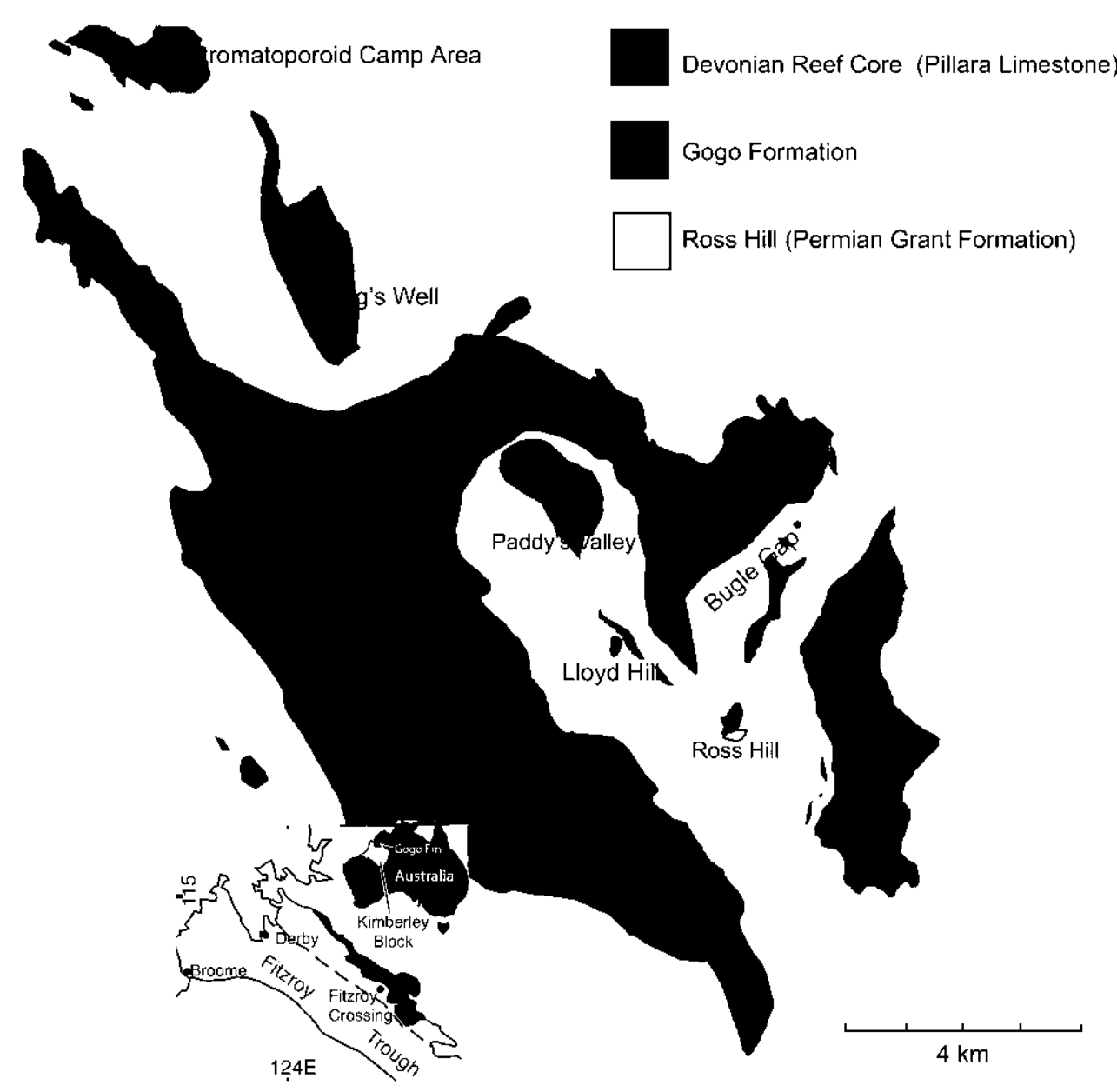

Figure 1 Simplified map of the Gogo Formation highlighting major nodule concentrations. Modified from an unpublished map supplied by Katherine Trinajstic.

floors where the Gogo Formation interfingers with the Saddler Formation in the region. The Gogo fish fauna is world renowned for its high diversity and outstanding threedimensional preservation (Long 2006; Long \& Trinajstic 2010).

Fossil actinopterygians in the Gogo Formation are comparatively common (pers. obs.) and typically comprise entire or near-complete articulated skeletons with three-dimensional preservation of both dermal and perichondral tissues. Actinopterygian specimens examined in this study were recovered from the following localities as detailed by Miles (1971, fig. 1): Embayment Hill, Stromatoporoid Camp, South of Lloyd Hill, Long's Well, Paddy's Valley (=Paddy's Spring Area of Miles 1971) and Bugle Gap.

\section{Material and methods}

\subsection{Fossil preparation}

All specimens collected and prepared during the course of this research were discovered as partially articulated skeletons within calcareous concretions that were evenly split in two in the field. Specimens were prepared using the acid transfer techniques of Toombs \& Rixon (1950). Half-nodules were mounted face-down in a slab of acrylic resin and prepared from the unexposed side. The matrix was removed by a series of immersions in a weak (c. $10 \%$ ) acetic acid solution. Protruding bones were reinforced with polyvinyl butyral ( ${ }^{\circledR}$ Mowital) diluted with ethanol. Principal acid preparation and restoration was carried out by the Museum Victoria preparator, $\mathrm{Mr}$ David Pickering. The end results were fully-exposed skeletons supported within clear acrylic bases. Specimens were whitened with ammonium chloride for microscope study and photography. Digital images of the fossils were supplied by Erich Fitzgerald (Figs 5, 7) and Lucinda Gibson (Fig. 17).

\subsection{Abbreviations}

Explanations of relevant anatomical abbreviations are presented in each figure caption. Anatomical terminology follows that of Gardiner et al. (2005) and Gardiner \& Schaeffer (1989). Although the skull roofing bones referred to herein as the frontal and parietal are homologous to the sarcopterygian parietal and postparietal respectively, traditional actinopterygian terminology is used to describe these elements to facilitate easy comparison with the majority of descriptive works on Devonian actinopterygians (Gardiner \& Bartram 1977; Gardiner 1984; Long 1988; Taverne 1997; Daeschler 2000; Prokofiev 2002; Friedman \& Blom 2006; Long et al. 2008; Choo et al. 2009).

In the following descriptions, the squamation is divided into the nine areas designated by Esin (1990) and employed by Trinajstic (1999a, b) to attribute isolated scales of Devonian actinopterygians to specific areas of the body. A diagrammatic map illustrating the approximate distribution of morphologically distinct scale types is presented in Figure 15.

Institutional abbreviations. ANU, Australian National University, Canberra; MV, Museum Victoria, Melbourne; NHMUK, The Natural History Museum, London; WAM, Western Australian Museum. 


\section{Systematic palaeontology}

Class Osteichthyes Huxley, 1880

Subclass Actinopterygii Cope, 1887

Family Mimiidae Gardiner, 1993

Remarks. Gardiner (1993) united Mimipiscis (= Mimia) from Gogo and Howqualepis from the Givetian of Victoria within Mimiidae, but did not provide a diagnosis for this new grouping. Subsequent studies have consistently failed to find a sister-group between these two genera exclusive to other early actinopterygians (e.g. Cloutier \& Arratia 2004; Friedman \& Blom 2006; Swartz 2009). Long et al. (2008) subsequently united Howqualepis and Donnrosenia from Antarctica in the novel family Howqualepididae. This analysis finds Mimipiscis and Gogosardina forming a distinctive clade of Late Devonian actinopterygians, together comprising a revised Mimiidae.

Diagnosis. Basal actinopterygian ('palaeoniscoid' grade) fishes with an open spiracular slit bordered by the intertemporal, dermosphenotic and supratemporal. Large pineal foramen present. Surangular absent. The dentary and angular meet on the smooth maxillary overlap surface in a zigzag suture. Parasphenoid lacks ascending processes. Anterior lepidotrichia of the pectoral fins are unsegmented for $40-60 \%$ of their length. Basal and fringing fulcra present. Flank scales with peg and socket articulation. Dorsal scutes extend from the occiput to dorsal fin. Genera include Gogosardina and Mimipiscis nom. nov.

\section{Mimipiscis nom. nov. \\ [= Mimia Gardiner \& Bartram, 1977]} 1977.

Type species. Mimipiscis toombsi Gardiner \& Bartram,

Etymology. For the Mimi dreamtime beings of Arnhem Land aboriginal folklore and the Greek piscis for fish.

Diagnosis. As for Mimia in Gardiner (1984) with the following amendments: Postrostral singular or absent. Pronglike anterolateral extension of the supratemporal contributes to the ventral margin of the spiracular opening. Anterior flank scales with anastomosing linear ridges. Porous dermal ornamentation absent. Body form is robust and fusiform.

Holotype. WAM 70.4.245.

Other specimens examined. WAM 86.9.687. MV P.221806, P.228267 and P.228268, along with uncatalogued MV and WAM specimens. NHMUK PV P.53225, PV P.53226, PV P.53228, PV P.53229, PV P.53232, PV P.53233, PV P.53237, PV P.53239, PV P.53240, PV P.53242, PV P.53243, PV P.53244, PV P.53245, PV P.53246, PV P.53247, PV P.53249, PV P.53252, PV P.53257, PV P.53258, PV P.56472, PV P.56473, PV P.56476, PV P.56484, PV P.56485, PV P.56486, PV P.56487, PV P.56488, PV P.56490, PV P.56491, PV P.56495, PV P.56497, PV P.56498, PV P.56503, PV P.56504, PV P.56507, PV P.56508, PV P.56509 and others.

\section{Mimipiscis toombsi (Gardiner \& Bartram, 1977) = Mimia toombsi Gardiner \& Bartram, 1977}

Diagnosis (emended). A Mimipiscis with approximately 75 scale rows, flank scales with prominent raised striae on the ganoine ridges. Postrostral absent. Tubercular ornament on anterior face of the rostral. Parasphenoid terminates at or just anterior to the ventral otic fissure. Small, pointed anterodorsal process on the suboperculum. Lateral margin of the posttemporal of much shorter length than anterior margin. Posterior
Zone E scales rectangular with well developed peg and socket. Anterior margins of the dorsal and anal fin directly aligned with one another.

\section{Description of Mimipiscis toombsi}

The dermal and neurocranial anatomy of Mimipiscis toombsi has been comprehensively described by Gardiner (1984). The scales were described by Trinajstic (1999b). Additional observations based on more recently prepared material are presented here.

\subsection{A large specimen of Mimipiscis toombsi}

An articulated actinopterygian was collected by John Long at Paddys Valley in 1986 and prepared at the Western Australian Museum. It was registered as WAM 86.9.687 as an example of Moythomasia durgaringa. The prepared specimen comprises a partially articulated fish mounted in resin, including the maxillae, palatoquadrate, lower jaws, opercular-gular series, pectoral girdle and scales representing about 40 transverse rows (Fig. 2).

A re-examination has established the specimen to be an example of Mimipiscis. There is no surangular. A zigzag suture of the dentary and angular is present on the maxillary overlap field. The porous ornamentation present on the scales, dentary and pectoral girdle of $M$. durgaringa is absent. As preserved, WAM 86.9.687 measures about $13.5 \mathrm{~cm}$ from the anterior tip of the maxilla to the rearmost visible scales. Scaling up from smaller, more complete specimens suggests an original length of a little over $20 \mathrm{~cm}$ from the snout to caudal inversion, considerably in excess of the $15 \mathrm{~cm}$ maximum size stated by Gardiner (1984). This makes the specimen one of the largest of Gogo actinopterygians, exceeded only by a few individuals of Moythomasia.

The dermal osteology has no visible differences in shape or proportions to larger (10 $\mathrm{cm}$ or greater) specimens of Mimipiscis toombsi. The suboperculum has a small anterodorsal process, there are raised striae on the ridges of the flank scales and there are about 40 scale rows anterior to the dorsal fin (suggests a total of less than 80 vertical scale rows). WAM 86.9.687 is thus assigned to $M$. toombsi.

There are, however, notable differences in the dermal ornamentation of WAM 86.9.687 to other specimens of this taxon. The ornament on the pectoral girdle comprises closely packed tubercles and very short ridges of ganoine that become more pointed on the ventral surface (Fig. 2b). This differs from the condition in most other individuals of $M$. toomsbi, where the cleithrum and clavicle possess long, well-spaced ridges (Gardiner 1984, fig. 126). There is also a region of tubercles on the supracleithrum in the centre and posteroventral margin of the bone. Elsewhere on this bone, the tubercular ornament changes to the linear arrangement more typical for this taxon (Gardiner 1984, fig. 125).

Isolated patches of short ridges and tubercles also appear scattered among the normally elongate ornamentation in some larger individuals of $M$. toombsi (NHMUK P.56491, P.56507 and others). The shortening of the ganoine ridges on the bones of some large specimens of this species appears to have been taken to extreme levels on the exceptionally large WAM 86.9.687. The scales of WAM 86.9.687 (Fig. 2c) are more densely ornamented with proportionally smaller ridges than in other examples, with the ridges terminating in up to 16 posterior serrations on the anterior scales versus the normally reported maximum of ten (Gardiner 1984; Trinajstic 1999b; both based on specimens less than $15 \mathrm{~cm}$ long). This is likely the result of ontogenetic variability, where the increase in scale 


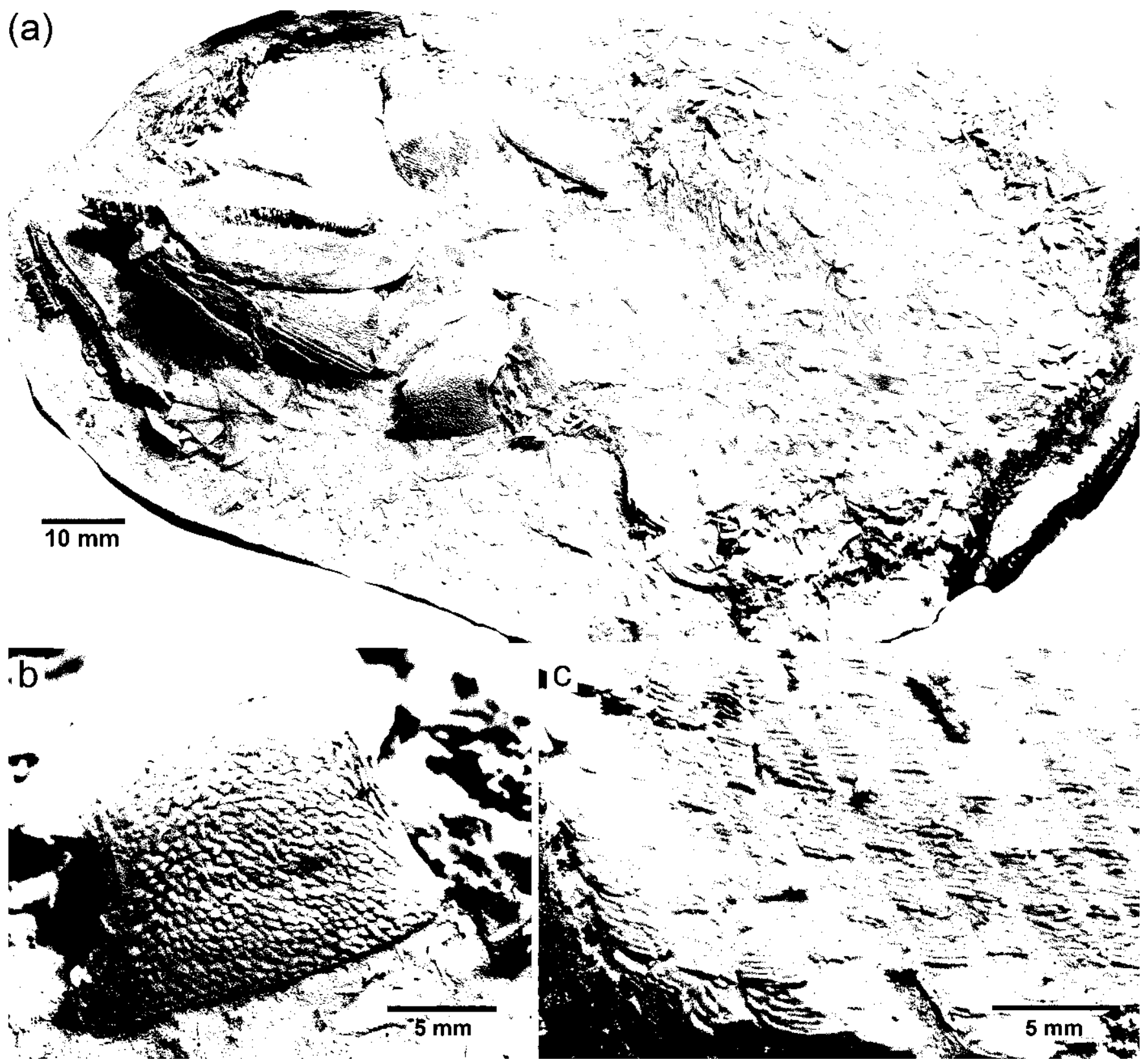

Figure 2 Mimipiscis toombsi. Photographs of WAM 86.9.687: (a) The entire specimen in left lateral view; (b)

View of ventral surface of cleithrum; (c) Detail of anterior flank scales.

size from smaller individuals does not correspond with an increase in the size of the ganoine ridges, with additional ridges developing to accommodate the greater scale area.

\subsection{The tail of Mimipiscis toombsi}

MV P.221806 was collected in 2005 by Tim Senden (ANU) at the area south of Lloyd Hill. It represents a complete specimen of Mimipiscis toombsi with an overall length of $11 \mathrm{~cm}$ (Fig. 3), and is notable for having a complete caudal fin. An examination of other specimens in Australian and NHMUK collections failed to produce another whole tail, with the lower hypochordal lobe usually incomplete or disrupted. Gardiner (1984) briefly describes the caudal fin as deeply cleft and inequilobate, restoring the tail accordingly (Gardiner 1984, fig. 145). The heterocercal tail of MV P.221806 has more than 55 closely-set primary lepidotrichia that are extensively segmented with distal branching. Both the upper notochordal mass and the lower hypochordal lobe are of a similar size and shape to each other, making the fin equilobate and functionally homo- cercal. A revised tail based on this information is presented on the lateral reconstruction of $M$. toombsi (Fig. 18b).

\subsection{Revised description of the parasphenoid of Mimipiscis toombsi}

A ventral view of the parasphenoid of NHMUK PV P.53247 was provided in the original description of Mimipiscis toombsi (Gardiner \& Bartram 1977, fig. 2; Gardiner 1984, fig. 50) which depicts the posterior section of the bone as a pair of narrow posterolateral arms flanking a small median shelf. Paired notches devoid of denticles, located at the juncture of the arms and the shelf, were interpreted as points of insertion for the subcephalic muscles (Gardiner 1984).

Examination of additional specimens of $M$. toombsi has shown that the posterior section of the parasphenoid of NHMUK PV P.53247 is broken posteriorly. The presence of a more extensive posterior shelf is indicated in a number of specimens (Fig. 4a, b), with a complete posterior margin being preserved on MV P.221806 (Fig. 4c, d). 

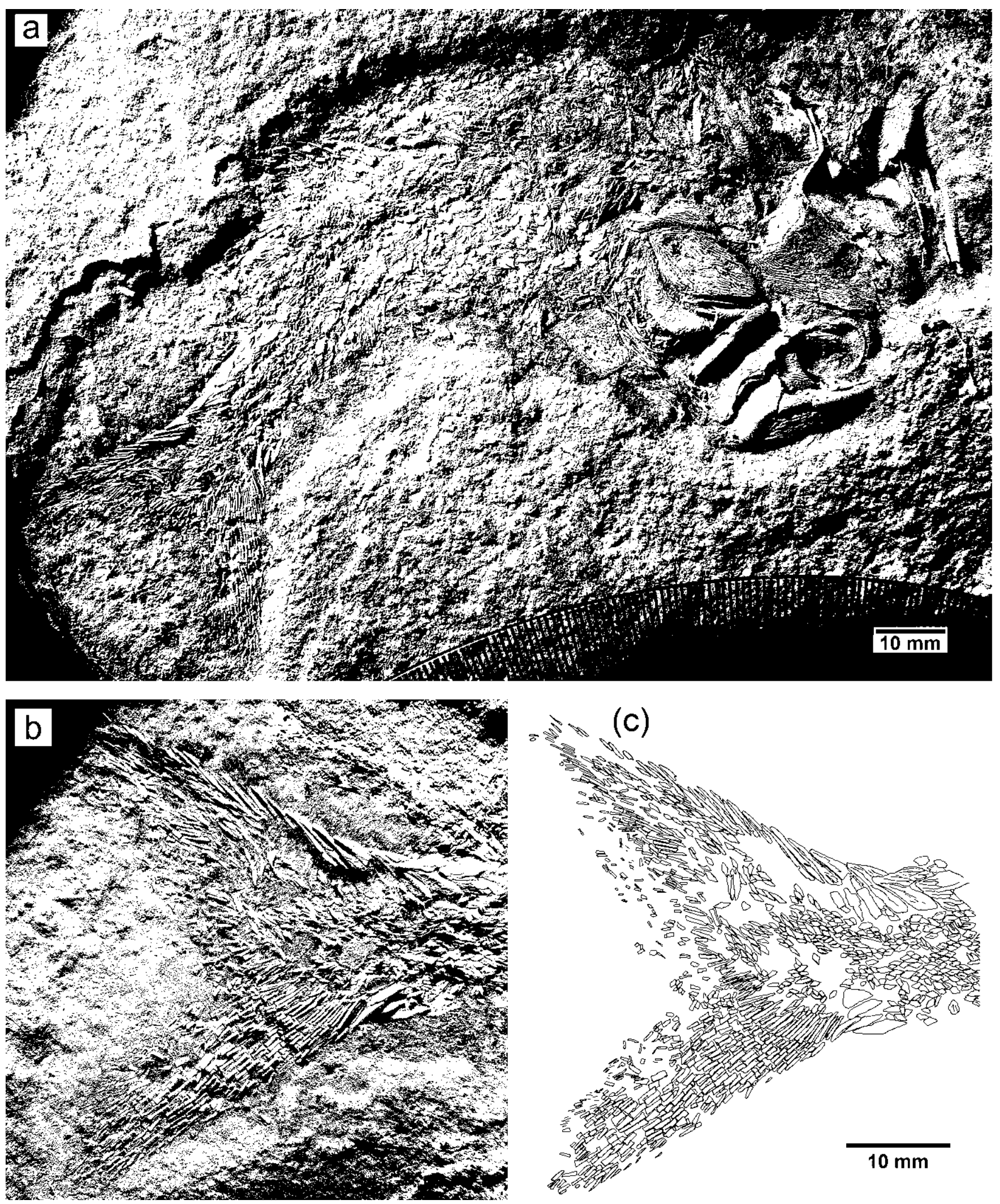

Figure 3 Mimipiscis toombsi. MV P.221806a: (a) Photograph of entire specimen. The fish has been flattened in right dorsolateral view; (b) photograph and (c) drawing of the caudal fin in right-lateral view.

The anterior, multifid section consists of a narrow, median tongue flanked by two broader lobes with a variable degree of further subdivision. In some specimens, these lobes branch into a number of small, digitate subdivisions (eg. NHMUK PV P53247, Fig. 4e); in others they form discrete, squaretipped lobes (eg. NHMUK PV P.53223, Fig. 4a).

The posterior section of the parasphenoid forms a depressed triangular shelf. From an area just aft of the bucco- hypophysial canal, the shelf flares outwards in a delta-wing shape. The posterolateral tips of this shelf have a slight dorsal flexure and in some specimens may extend to below and behind the spiracular canal. Medially, the posterior shelf terminates at or just anterior to the level of the ventral otic fissure, in a smooth posterior edge that in some specimens is folded into a number of small, finger-like projections. The entire buccal surface of the posterior section is covered in small denticles. 

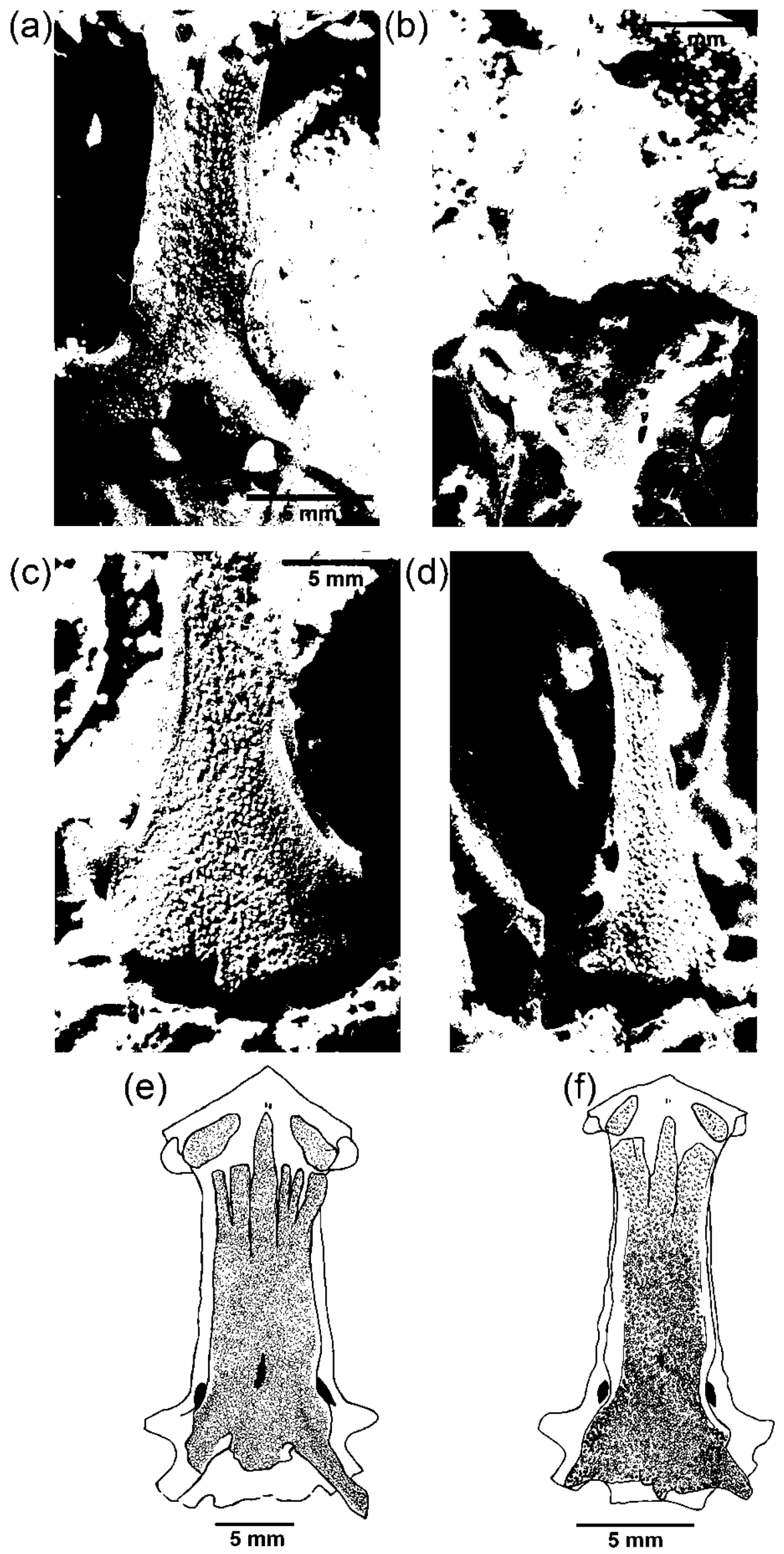

Figure 4 Parasphenoids of Mimipiscis toombsi: (a) photograph of parasphenoid of NHMUK PV P.53223 in ventral view. The bone is complete save for a small median section of the posterior shelf; (b) posterior section of the parasphenoid of MV P.227028 in ventral view; (c) Posterior and (d) left lateral views of the parasphenoid of MV P.221806b. The anterior $25 \%$ of the bone is missing; (e) reconstruction of the parasphenoid of NHMUK PV P.53247 as presented by Gardiner and Bartram (1977). Grey line added to delineate probable original full extent of the posterior shelf; (f) reconstruction of the complete parasphenoid of Mimipiscis toombsi. Based on NHMUK PV P.53247 with missing sections of the posterior shelf based on MV P.221806b. 
Thus, the posterolateral arms and small median section presented in the original description (Fig. 4e) actually consists of the remnants of a large, triangular posterior shelf, the "arms" representing the lateral margins of this shelf (Fig. 4f). The unornamented sections described as attachment areas for the subcephalic muscles by Gardiner are probably the result of damage to the parasphenoid of NHMUK PV P.53247. They are not visible on any specimen in which the posterior section is complete.

This revised reconstruction of the parasphenoid of $M$. toombsi displays a greater degree of similarity to that of Moythomasia durgaringa (Fig. 14c) which also has a depressed, denticulated posterior shelf. Unlike Moythomasia, the posterior shelf of $M$. toombsi is not flanked by ascending processes, nor are there recesses for paired parotic toothplates (Gardiner 1984, fig. 51).

\section{A new species of Mimipiscis from the Gogo Formation}

\subsection{Systematic palaeontology}

Mimipiscis bartrami sp. nov.

(Figs 5-19)

1977 Mimia toombsi (in part); Gardiner \& Bartram, figs 2, 2B (occipital and otic region incorporated into composite reconstruction).

1977 'palaeoniscoid'; Nicoll, figs 2, 3.

1984 Mimia toombsi (in part); Gardiner, figs 3, 6, 14, 16, 20, 50 (occipital and otic region incorporated into composite reconstruction), 82, 121, 122, 127.

2008 Mimia sp. nov; Long, Choo \& Young.

2010 New species of 'Mimia'; Long \& Trinajstic. Fig. 5a.

Locality and horizon. The nodule fields at Stromatoporoid Camp Area, Long's Well, Paddy's Valley and Bugle Gap (see Fig. 1 and Miles 1971, fig. 1 for a more detailed map), Gogo Formation, Late Devonian (lower Frasnian), near Fitzroy Crossing, Western Australia. Isolated scales probably referrable to this taxon are present in the Gneudna Formation of the Late Devonian of Western Australia (Kate Trinajstic pers. comm. 2010).

Etymology. For the late Alan Bartram in recognition of his pioneering work on Mimipiscis toombsi and other fossil actinopterygians.

Diagnosis. A Mimipiscis with approximately 110 scale rows, flank scales without raised striae on the ganoine ridges. Single postrostral present. Vermiculate ornament on small rostral. Posterior shelf of parasphenoid extends past the ventral otic fissure. Long, prong-like anterodorsal process on suboperculum. Length of lateral margin of posttemporal more than half that of the anterior margin. Anterior margin of the anal fin posterior to that of the anterior margin of the dorsal fin. Posterior Zone E scales are tall and narrow, lacking peg-andsocket articulation.

Holotype. WAM 08.9.1 $(\mathrm{a}+\mathrm{b})$ : An almost complete body and head with incomplete braincase preserved in counterpart (Figs 5, 6, 7, 13, 16). Collected in 2005 by the author at Bugle Gap.

Other material. MV P.227027 $(\mathrm{a}+\mathrm{b})$ : Partial skull with fragmentary braincase. Articulated postcranium, lacking the tail (Figs 8, 9, 16). Collected in 2005 by John Long at Paddys Valley. MV P.228270 $(\mathrm{a}+\mathrm{b})$ : Almost complete fish, lacking tail (Figs 10b, 12). Collected in 1972 by Gavin Young at Paddys
Valley. ANU V1824: partially prepared almost complete fish (Fig. 10a) preserved with conodont elements in the body cavity that were subsequently removed and described by Nicoll (1977).

The following specimens in the NHMUK collection, originally identified as Mimia toombsi, are referred to Mimipiscis bartrami: PV P.53250, PV P.53254, PV P.53259, PV P.56489, PV P.56491, PV P.56492, PV P.56496, PV P.56500, 70.4.246 (a WAM designation?). Additional uncatalogued and unprepared specimens collected from the Gogo Formation in 2008 and housed within the MV and WAM collections are likely referrable to this taxon.

\section{Description of Mimipiscis bartrami sp. nov.}

\subsection{Snout}

The rostral (Figs 7, 12) is short and of a similar size to each of the paired premaxillae. It sutures posteriorly with the postrostral at a wavy margin. There is a narrow, unornamented overlap surface for the anterior margin of the postrostral. A recess for the anterior nasal opening corresponds to a sharp ventral downcurve, forming a rounded protruding snout-tip. The bone narrows anteriorly to a tip that is set against the median premaxillary suture. Dermal ornamentation consists of an irregular vermiculate pattern of ganoine ridges, the anteroventral tubercles that are present on the rostral of $M$. toombsi (Gardiner 1984, fig. 42) are absent. The ethmoidal commisure is visible externally as an arc of small pores.

The premaxilla (Figs 7, 11) is small and flat, forming the occlusal margin of the snout with its opposite number. There is a single row of pointed, conical teeth inwards of a row of much smaller accessory teeth on the outer edge. Acrodin caps are visible on the largest teeth of all dermal occlusal margins. The premaxillae meet in a short median suture, forming a smooth v-shaped recess that excludes the rostral from the jaw margin. The infraorbital sensory canal enters near the posterior edge of the bone and exits the anterodorsal margin midway through the suture with the rostral. Ornamentation consists of short posterolaterally directed ridges that grade into tubercles at the biting edge.

The nasals (Figs 7,11 ) are long bones, situated lateral to the postrostral, which narrow posteriorly to suture with the dermosphenotic. The dorsal margin is straight, save for a notch for the anterior nasal opening. The concave lateral margin forms the anterodorsal border of the orbit. Ornament consists of longitudinal ridges along the dorsal lamina, grading towards smaller ridges closer to the anterior margin. The supraorbital sensory canal is visible as a longitudinal row of small pores with a short anterior pit-line adjacent to the anterior nasal opening. The nasals are effectively identical to those of M. toombsi (Gardiner 1984, fig. 43).

\subsection{Skull roof}

The skull roof of Mimipiscis bartrami contains paired frontals, intertemporals, parietals, dermosphenotics and supratemporals, along with a single postrostral. The dermal ornamentation of all skull roofing bones is composed primarily of rostrocaudally directed linear ridges.

The postrostral (Figs 7, 12) is a rectangular bone that occupies a similar area to the dorsal lamina of the rostral of $M$. toombsi, and accounts for about $20 \%$ of the skull length in dorsal view. It sutures posteriorly to the frontals and laterally with the nasals. Unlike the similarly shaped postrostral of Kalops (Poplin \& Lund 2002), there is no contribution to the posterior nasal openings. It differs from Gogosardina which has 

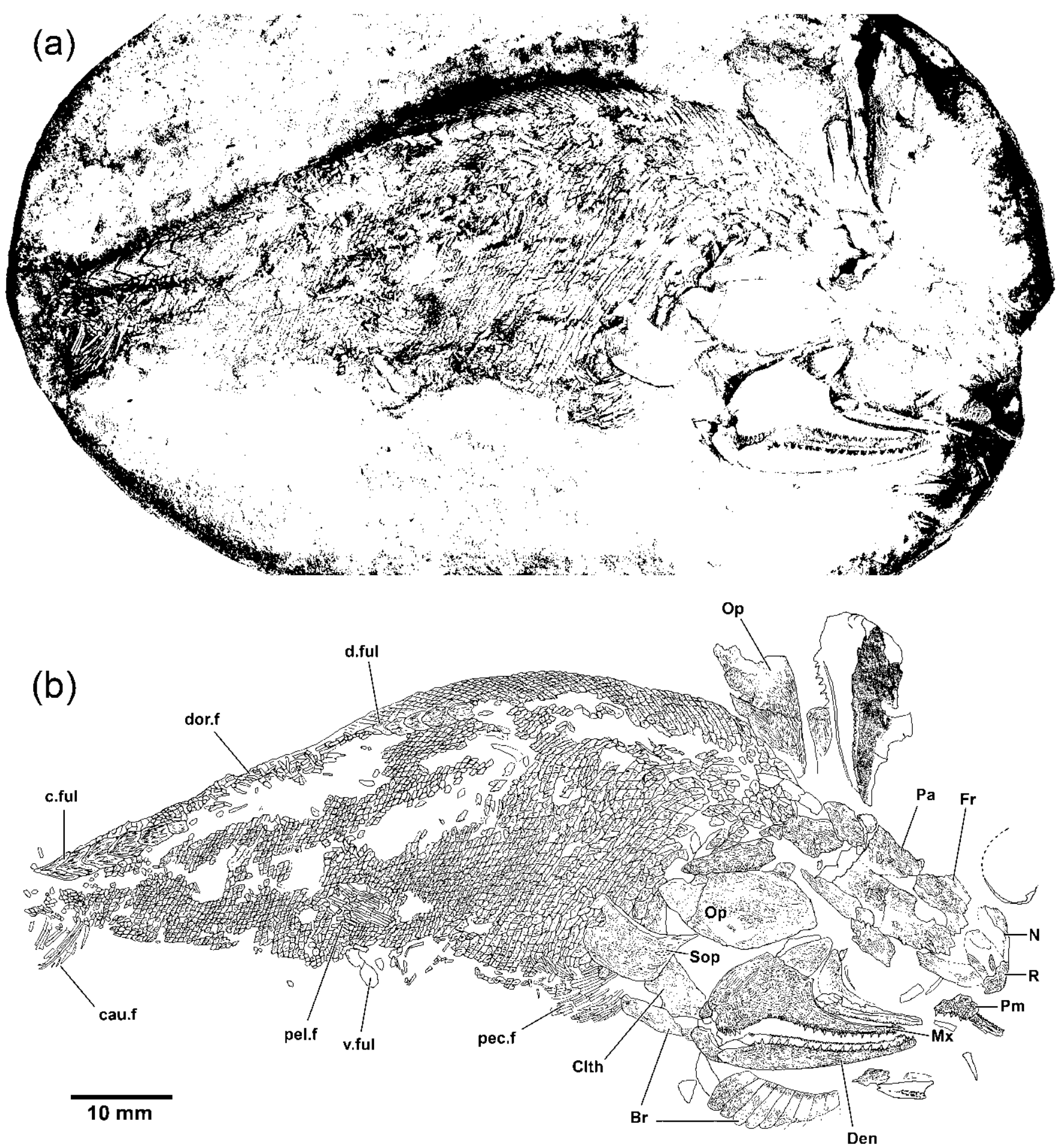

Figure 5 Mimipiscis bartrami sp. nov.: (a) photograph and (b) interpretive drawing of WAM 08.9.1a (holotype) in right lateral view. Abbreviations: $\mathrm{Br}=$ branchiostegal rays; Clth=cleithrum; c.ful=caudal fulcra/scutes; cau.f =caudal fin; d.ful=dorsal fulcra/scutes; Den=dentary; dor.f=dorsal fin; Fr=frontal (=sarcopterygian parietal); $\mathrm{Mx}=$ maxilla; $\mathrm{N}=$ nasal; $\mathrm{Op}=$ operculum; $\mathrm{Pa}=$ parietal (= sarcopterygian postparietal); pec $\mathrm{f}=$ pectoral fin; pel. $\mathrm{f}=$ pelvic fin; $\mathrm{Pm}=$ premaxilla; $\mathrm{R}=$ rostral; Sop=suboperculum; .ful=ventral fulcra/scutes.

a series of four small postrostrals that contribute to the margin of the pineal foramen (Choo et al. 2009).

The paired frontals and parietals are of similar length, differing from the condition in $M$. toombsi where the frontals are the largest bones on the skull roof (Fig. 7). They narrow anteriorly towards an irregular margin that forms a v-shaped recess for the postrostral. An excavation for the large pineal foramen is present halfway down the smooth medial margin. The supraorbital canal enters the bone in the middle of the posterior margin and is deflected laterally at the level of the pineal foramen, exiting anterolaterally into the nasal.
Each parietal (Figs 7, 11) is roughly rectangular in outline, with a smooth median margin. The bone has a jagged anterior margin where it contacts the frontal. The three pit lines are fully separated, the anterior being the smallest and is continuous with the supraorbital canal, exiting the bone via a tongueshaped projection as with M. toombsi (Gardiner 1984, fig. 80). Ornament consists of long, rostrocaudally directed linear ridges that are deflected by the pit lines.

The triangular intertemporal (Fig. 11) is the smallest bone in the skull roof and is about one half the length of the parietal. It sutures with the frontal medially, the parietal posteromedially 

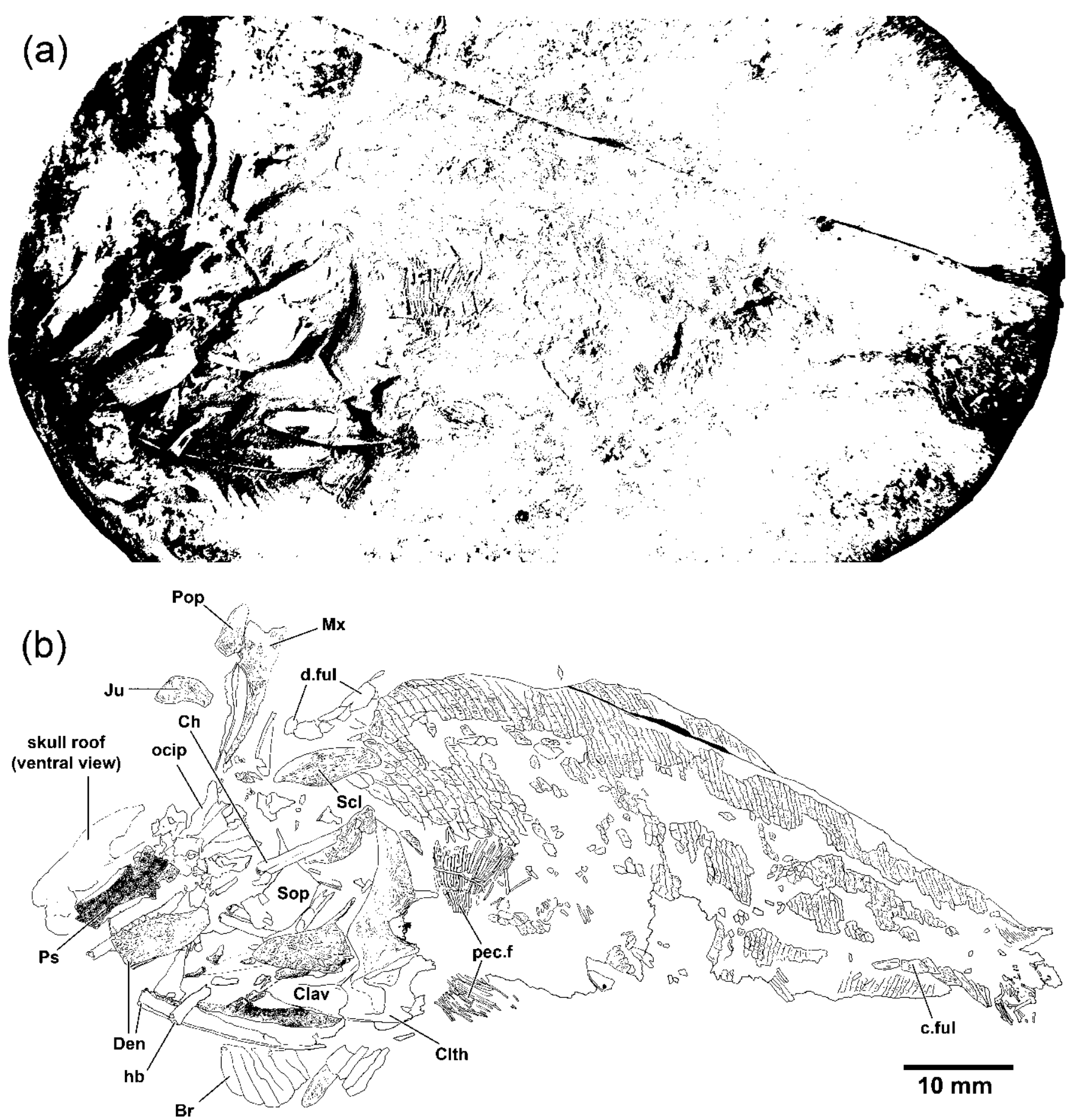

Figure 6 Mimipiscis bartrami sp. nov.: (a) photograph and (b) interpretive drawing of WAM 08.9.1b (holotype counterpart) in left-lateral view. Abbreviations: $\mathrm{Br}=$ branchostegal rays; $\mathrm{Ch}=$ ceratohyal; $\mathrm{Clav}=$ clavicle; Clth=cleithrum; c.ful=caudal fulcra/scutes; d.ful=dorsal fulcra/scutes; Den=dentary; hb=hypobranchial; $\mathrm{Ju}=$ jugal; $\mathrm{Mx}=$ maxilla; ocip=occipital ossification; pec. $\mathrm{f}=$ pectoral fin; $\mathrm{Pop}=$ preoperculum; $\mathrm{Ps}=$ parasphenoid; $\mathrm{R}=$ rostral; $\mathrm{Scl}=$ supracleithrum; $\mathrm{Sop}=$ suboperculum.

and the supratemporal posteriorly. The sensory canal exits the bone posteriorly into the supratemporal and anterolaterally into the dermosphenotic.

The supratemporal (Fig. 11) is narrow; situated lateral to the parietal and posterior to the intertemporal. As with $M$. toombsi (Gardiner 1984, fig. 82), there is an anterolateral flange that forms the posterior margin of the spiracular opening. The sensory canal traverses the bone near the lateral margin, presumably originating in the extrascapular and continuing anteriorly into the intertemporal.

The dermosphenotic, as in M. toombsi (Gardiner 1984, fig. 68), is a T-shaped, roughly triangular bone that meets the posterior edge of the nasal via a shelf-like anterior ramus. There is a narrow ventral extension suturing with the anterodorsal margin of the jugal. The posterior ramus is a short, narrow structure whose dorsal surface has an excavation for the anterolateral margin of the spiracular opening. The configuration of the infraorbital sensory canal is identical to that of $M$. toombsi, entering in the dorsal margin from the intertemporal, exiting ventrally into the jugal and with a short anterior branch.

There is a single pair of extrascapulae (Fig. 7) that meet medially in a short suture, although the bones do not narrow medially (towards the midline of the skull) as much as those of M. toombsi (Gardiner 1984, fig. 84). 
(a)

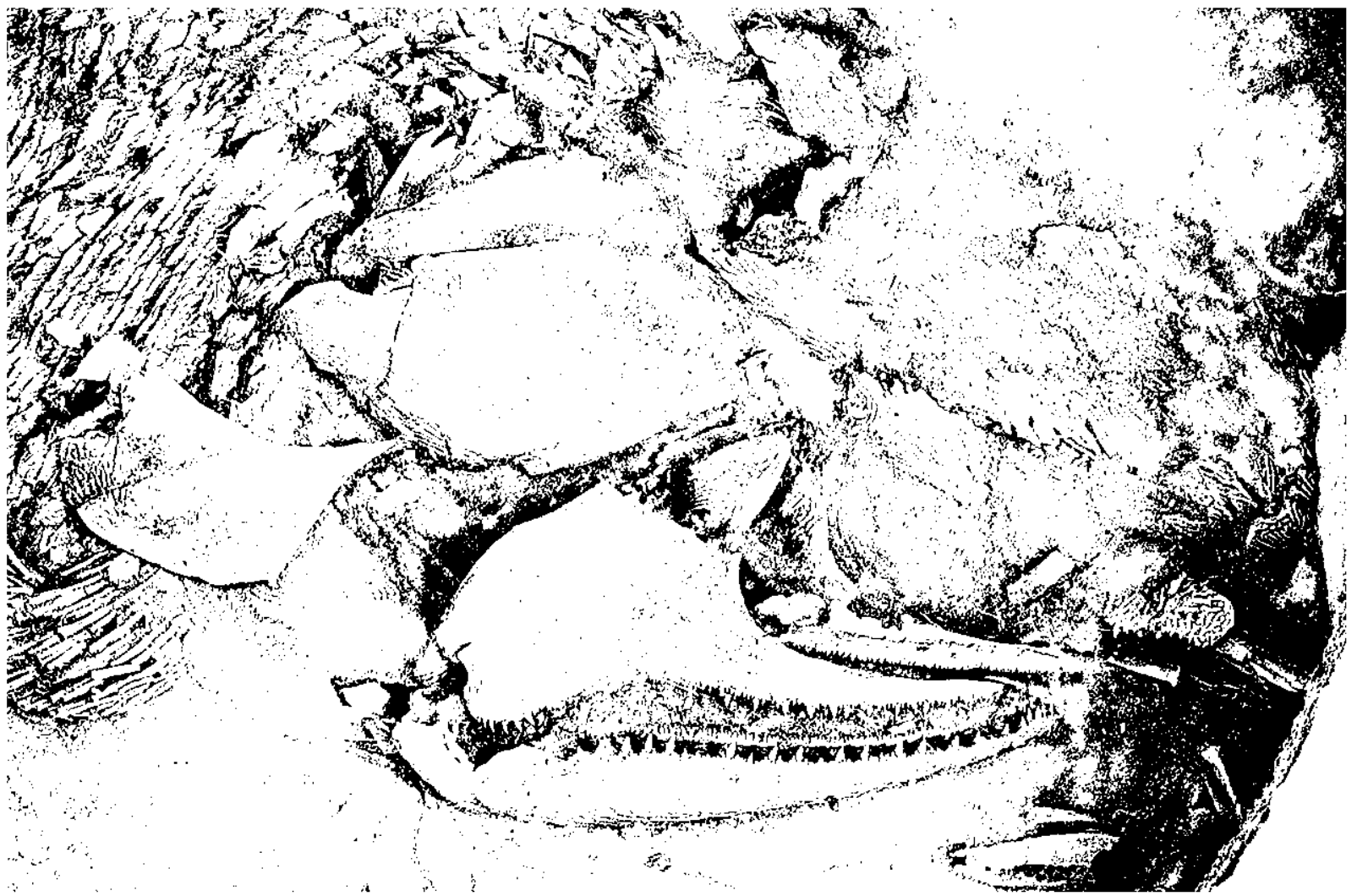

(b)

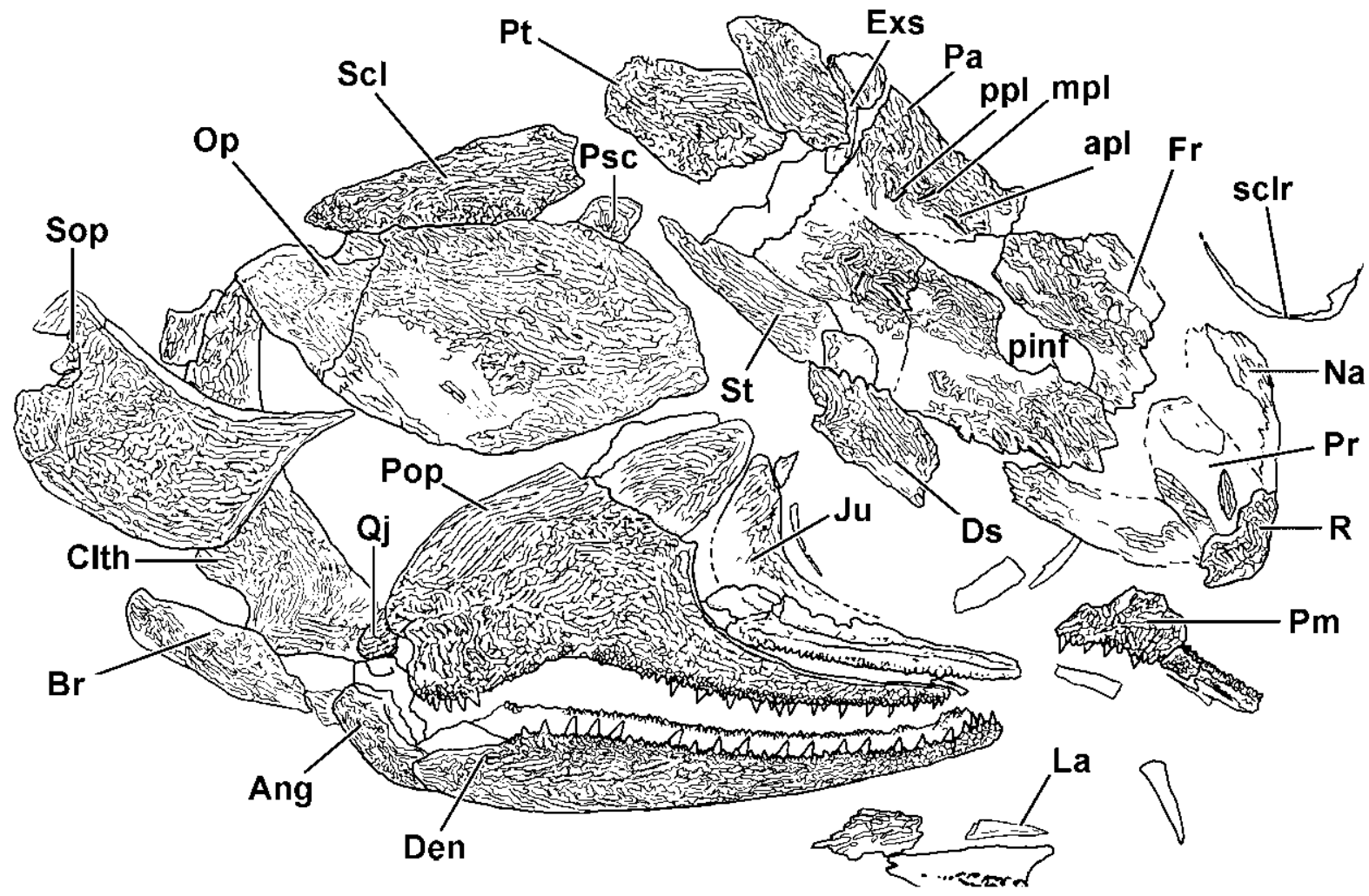

$10 \mathrm{~mm}$

Figure 7 Mimipiscis bartrami sp. nov.: (a) photograph and (b) interpretive drawing of the skull of WAM 08.9.1a (holotype) in right-lateral view. Abbreviations: $\mathrm{Ang}=$ angular; apl=anterior pit-line; $\mathrm{Br}=$ branchiostegal rays; Clth=cleithrum; Den=dentary; Ds=dermosphenotic; Exs=extrascapular; $\mathrm{Fr}=$ frontal $(=$ sarcopterygian parietal); Ju=jugal; $\mathrm{La}=$ lacrimal; $\mathrm{mpl}=$ middle pit-line; $\mathrm{Na}=$ nasal; $\mathrm{Op}=$ operculum; $\mathrm{Pa}=$ parietal (=sarcopterygian postparietal); $\operatorname{pinf}=$ pineal foramen; $\mathrm{Pm}=$ premaxilla; $\mathrm{ppl}=$ posterior pit-line; Psc=presupracleithrum; Pop= preoperculum; $\mathrm{Pr}=$ postrostral; $\mathrm{Pt}=$ posttemporal; $\mathrm{Qj}=$ quadratojugal; $\mathrm{R}=$ rostral; $\mathrm{Scl}=$ supracleithrum; sclr= sclerotic eye ring; $\mathrm{Sop}=$ suboperculum; $\mathrm{St}=$ supratemporal. 

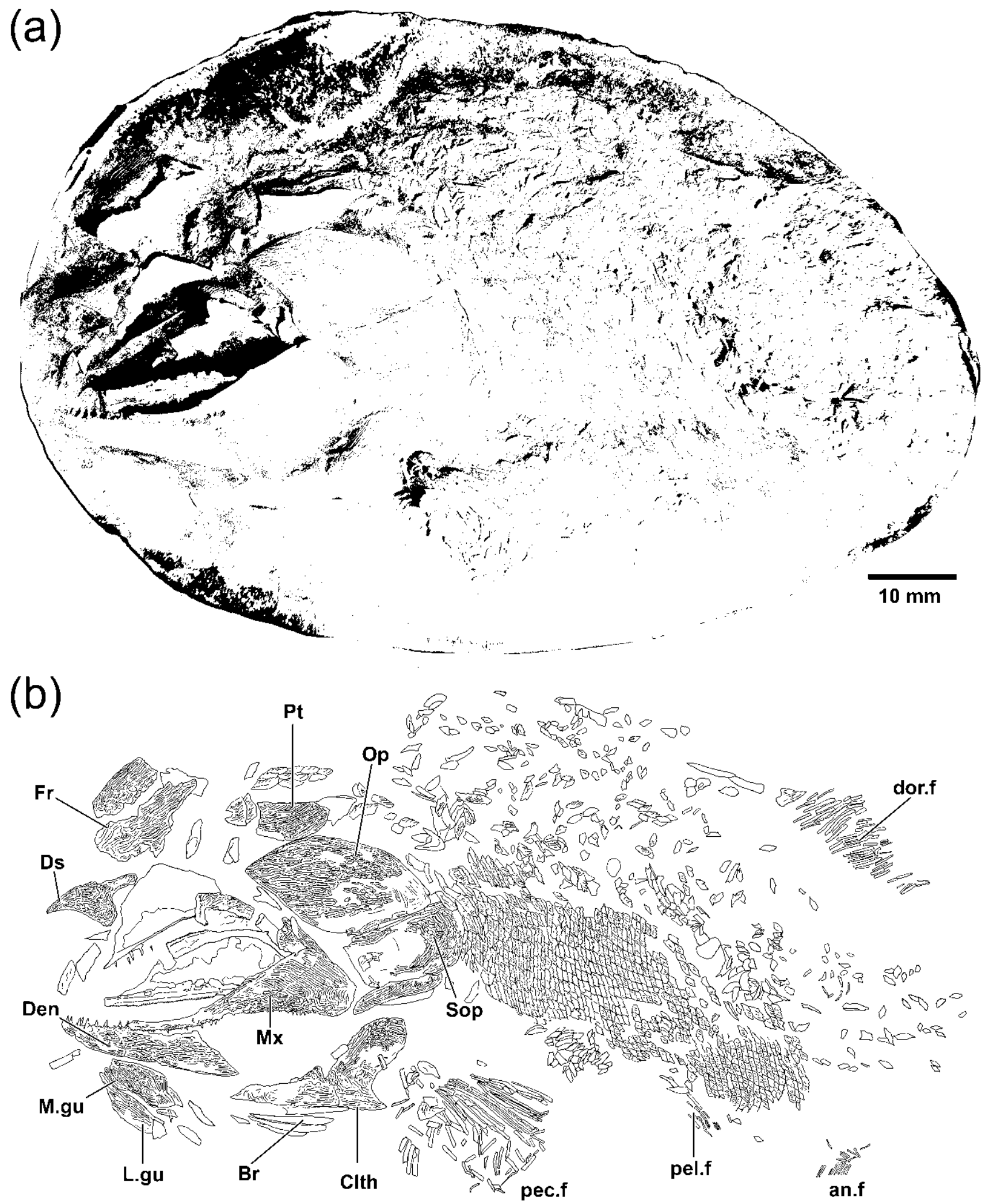

Figure 8 Mimipiscis bartrami sp. nov.: (a) photograph and (b) interpretive drawing of MV P.227027a in left-lateral view. Abbreviations: an $\mathrm{f}=$ anal $\mathrm{fin} ; \mathrm{Br}=$ branchostegal rays; $\mathrm{Clth}=$ cleithrum; $\mathrm{Den}=$ dentary; dor.f=dorsal fin; Ds=dermosphenotic; $\mathrm{Fr}=$ frontal; L.gu=lateral gular; $\mathrm{M} . \mathrm{gu}=$ median gular; $\mathrm{Mx}=$ maxilla; $\mathrm{Op}=$ operculum; pec.f = pectoral fin; pel. $\mathrm{f}=$ pelvic fin; $\mathrm{Pt}=$ posttemporal; $\mathrm{Sop}=$ suboperculum.

\subsection{Cheek and infraorbitals}

The palatoquadrate (Fig. 11a) is long and roughly triangular, and is very similar to that of Mimipiscis toombsi (Gardiner 1984, fig. 56). The dermal elements on the medial surface of palatoquadrate are fully ossified in all specimens, making the isolation of individual bones impossible. It is covered in numerous minute teeth, except for a single row of large pointed teeth on the fluted dermopalatine series. There is no evidence for accessory vomerine toothplates.

There are two infraorbitals: the jugal and lacrimal. The jugal (Fig. 7) is a crescentic bone that tapers anteroventrally to meet the lacrimal, while the convex posteroventral margin overlaps 


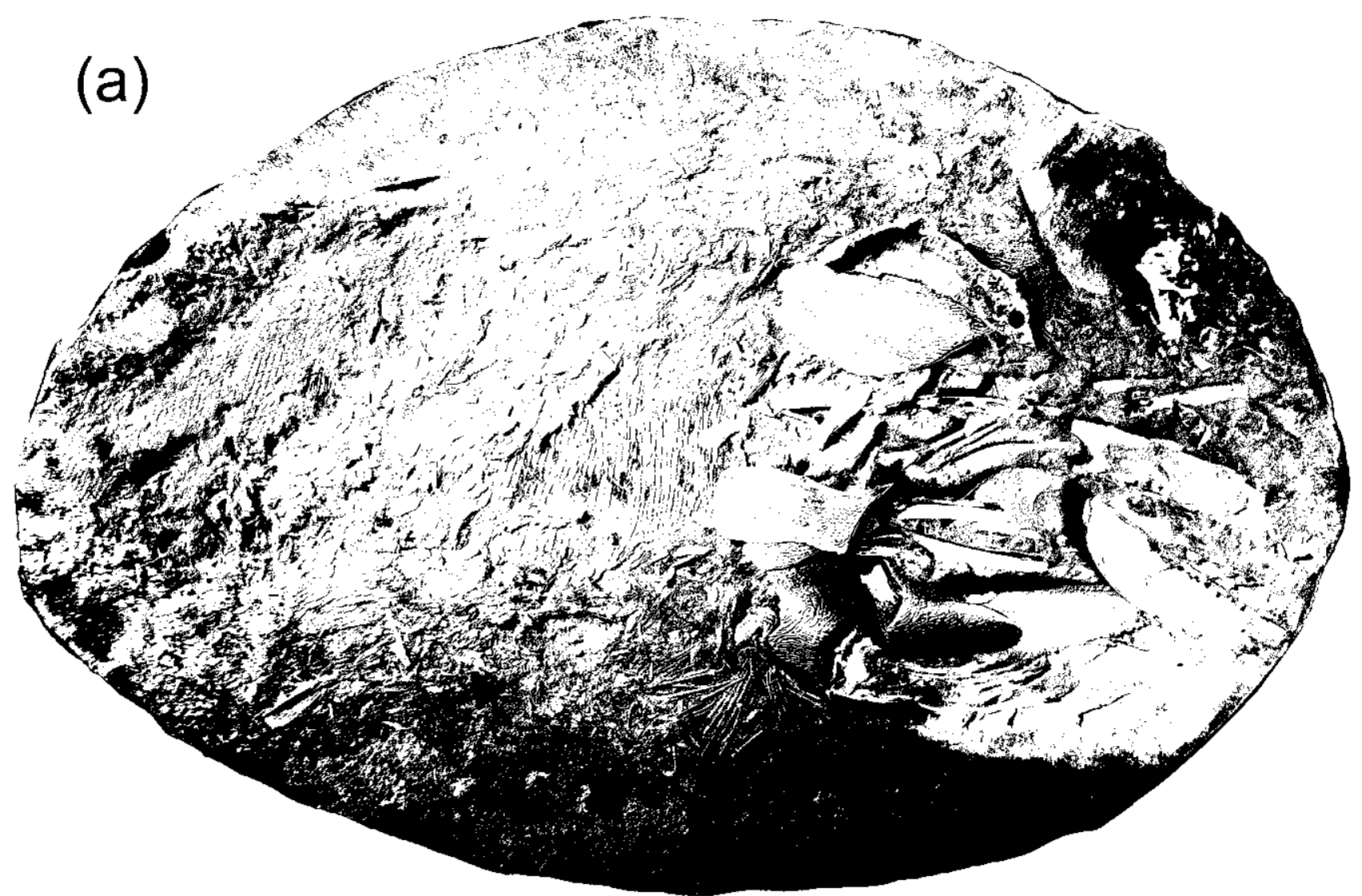

(b)

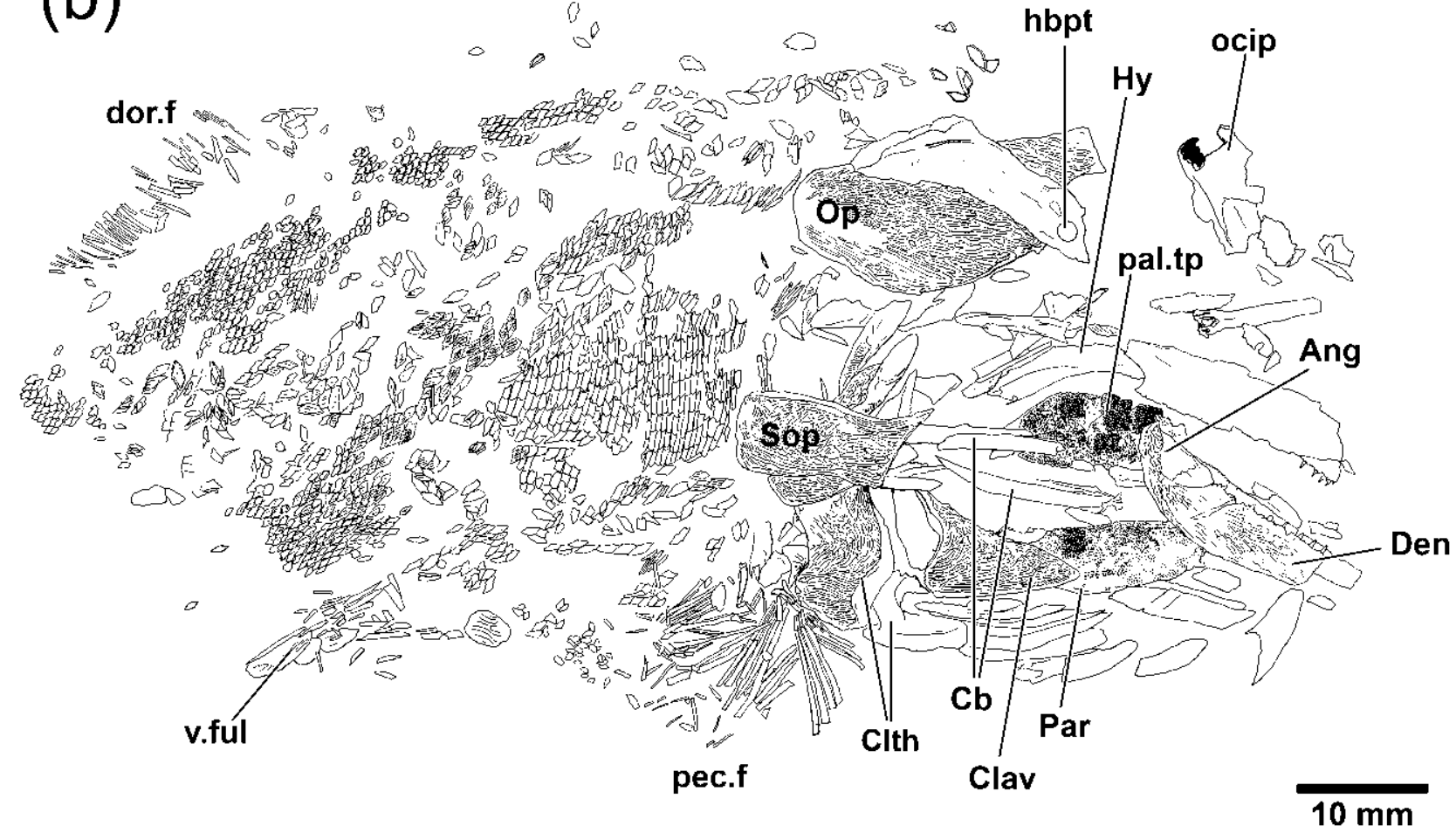

Figure 9 Mimipiscis bartrami sp. nov.: (a) photograph and (b) interpretive drawing of MV P.227027b in right-lateral view. Abbreviations: Ang=angular; $\mathrm{Cb}=$ ceratobranchial; Clav=clavicle; $\mathrm{Clth}=$ cleithrum; Den=dentary; dor.f $=$ dorsal fin; $\mathrm{hbpt}=$ hole for basipterygoid process; $\mathrm{Hy}=$ hyomandibular; ocip=occipital ossification; Par=prearticular; pal.tp=toothplate series of palatoquadrate; pec.f=pectoral fin; Sop=suboperculum; v.ful=ventral fulcra/scutes.

the edges of the preoperculum and maxilla. The orbital margin is evenly concave with no notch. The infraorbital canal shifts from a near vertical to a near horizontal orientation within the bone. Ornament comprises short to medium linear ridges that follow the contour of the orbit near the anterodorsal margin, becoming more rostrocaudally directed on the remainder of the bone. A right lacrimal is preserved in mesial view on the holotype (Fig. 7). As with the lacrimal of M. toombsi (Gardiner 1984, fig. 72), it is a small thin bone that tapers anteriorly. The infraorbital sensory canal runs the entire length of the bone. 


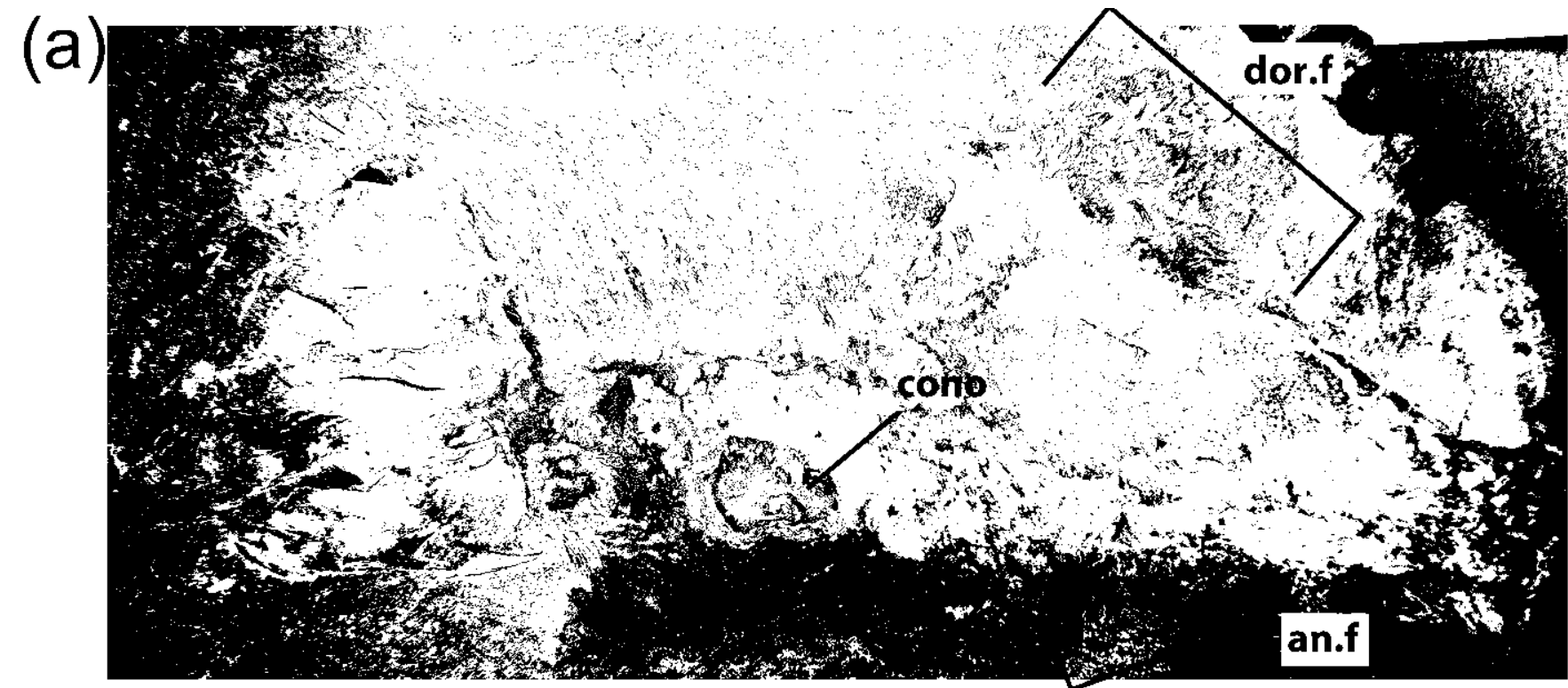

(b)

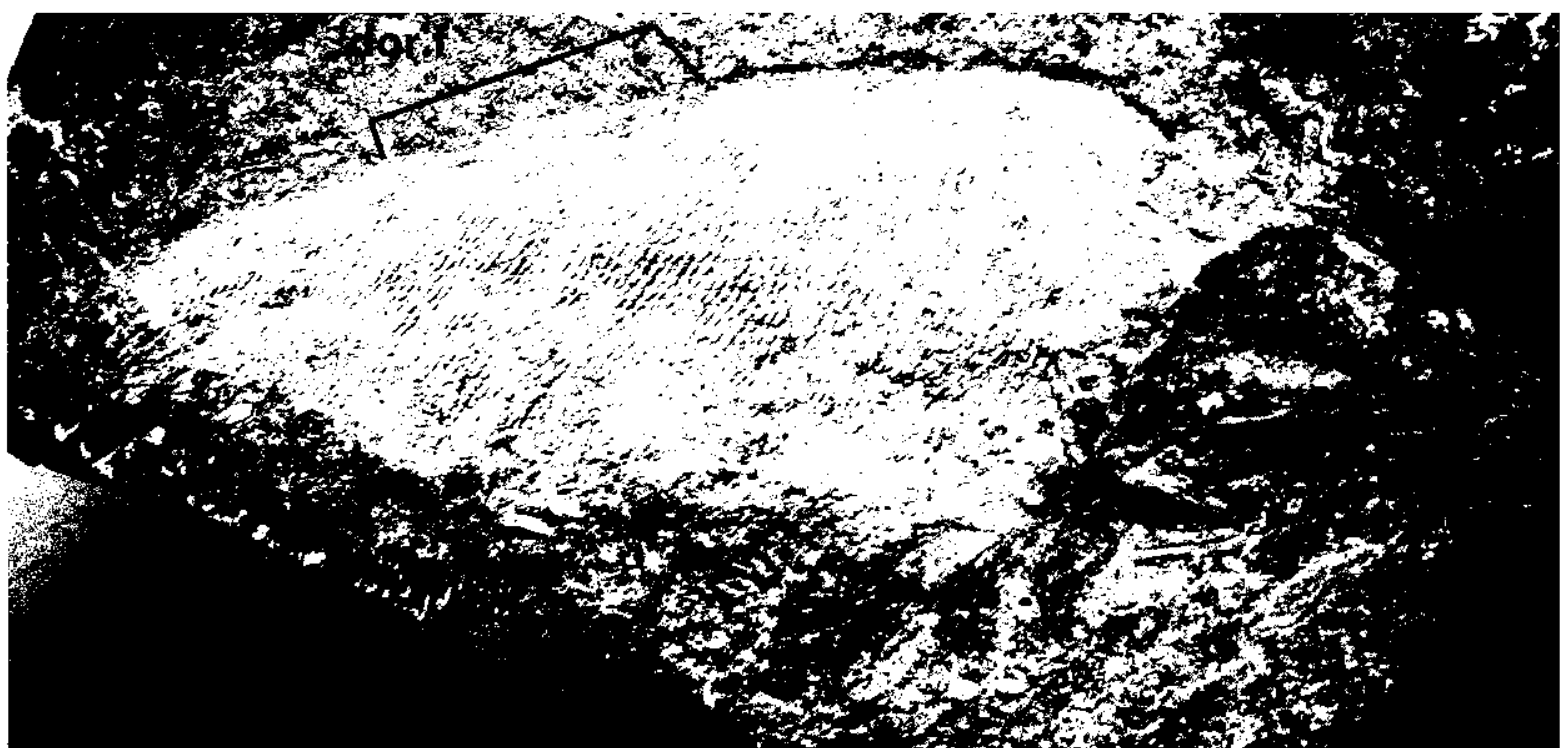

$10 \mathrm{~mm}$

Figure 10 Mimipiscis bartrami sp. nov.: (a) photograph of ANU V1824. This specimen along with the conodont elements recovered from the gut cavity were described by Nicoll (1977); (b) photograph of MV P.228270 in right lateral view prior to preparation. Abbreviations: an $. \mathrm{f}=$ anal fin; $\mathrm{cono}=$ area from which conodont elements were removed; den=dentary; dor. $\mathrm{f}=$ dorsal fin.

\subsection{Neurocranium and parasphenoid}

The neurocranium of Mimipiscis bartrami has been figured and described by Gardiner as that of Mimia toombsi. Two NHMUK neurocrania referrable to $M$. bartrami (based on associated dermal bone and squamation) are figured in Gardiner (1984): PV P.53259 (Gardiner 1984, figs 14, 16, 20) and PV P.56496 (Gardiner 1984, figs 3, 6). Additionally, the otic and occipital region of PV P.56496 is incorporated in a composite reconstruction with the $M$. toombsi specimen PV P.53247 (Gardiner 1984, fig. 50). Beyond individual variation, there appear to be no consistent differences between the braincases of the two species, although future work involving CT tomography may reveal as yet unrecognised diagnostic features.

The parasphenoid and the associated basisphenoid are visible in ventral view on the holotype (Figs 6,13) as a slender, rectangular element. As with the parasphenoids of Cheirolepis (Pearson \& Westoll 1979) and Mimipiscis toombsi, there are no ascending processes. Except where described below, the buccal surface is covered in minute, tooth-like denticles.

Anterior to the basipterygoid processes, the parasphenoid is blade-shaped. The bone flares rostrally to terminate at a tripartite structure of two broad square-tipped extensions lying immediately adjacent to a narrow, median ramus whose anterior tip is not preserved. The left (right in ventral view) lateral anterior extension of the holotype is further subdivided on the smooth lateral margin into multiple digitate structures. The anterior parasphenoid is similar in overall form to that of Mimipiscis toombsi (Fig. 4a) and differs from the anterior tripartite extensions of Moythomasia durgaringa and Howqualepis (Fig. 14), in which the lateral extensions are widely separated from the median tongue. The buccohypophyseal opening is roughly level with the basipterygoid processes. There are small square-tipped lateral extensions of the parasphenoid on the basipterygoid processes which are absent in M. toombsi. 

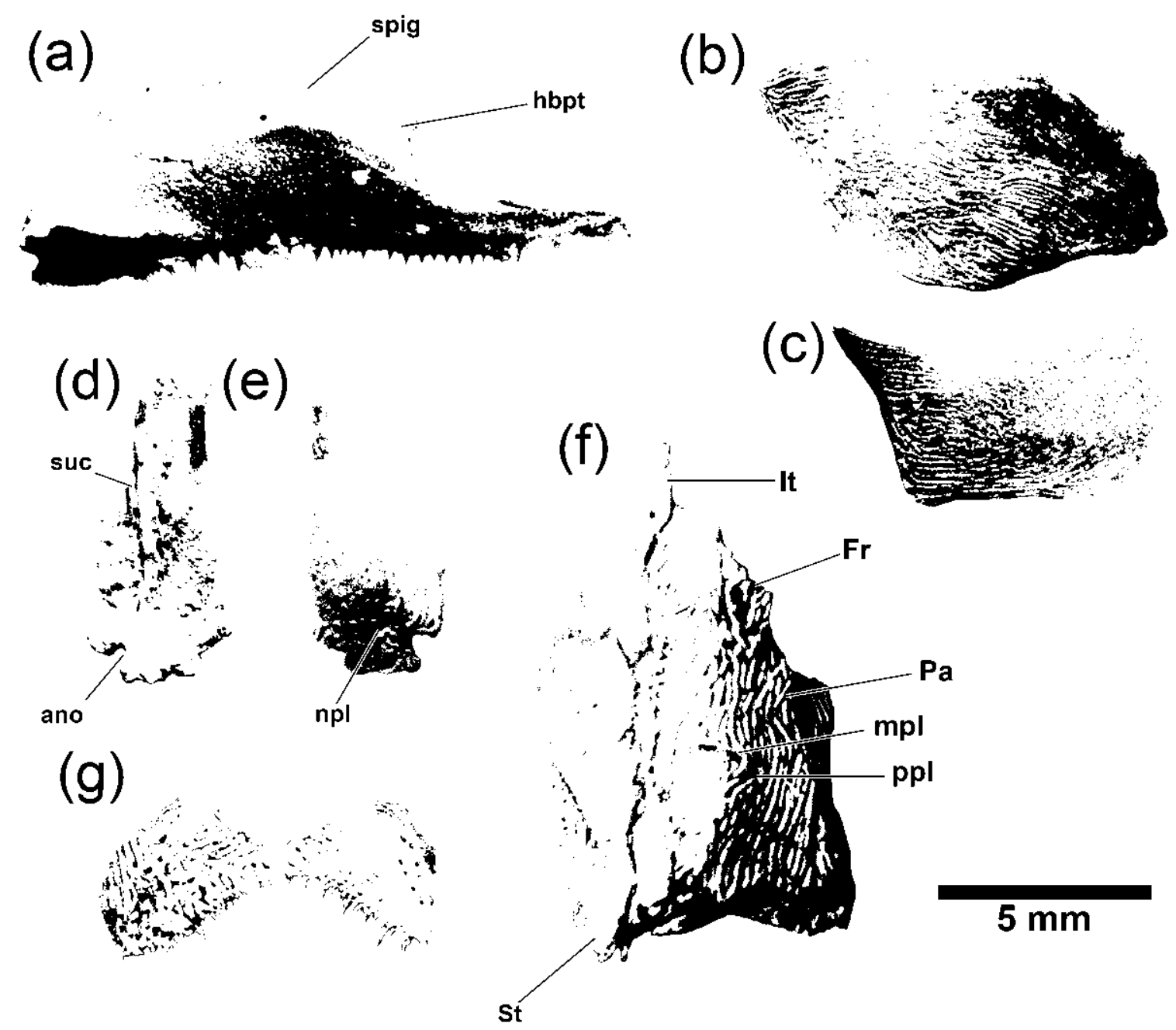

(g)
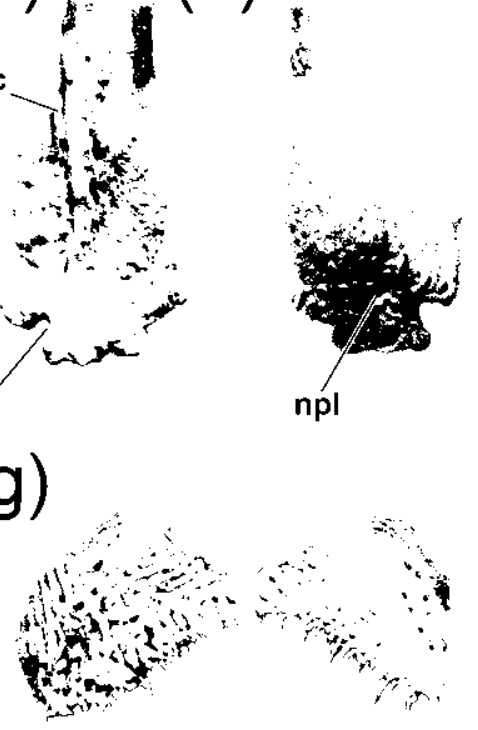

Figure 11 Mimipiscis bartrami sp. nov. Photographs of miscellaneous dermal skull elements: (a) NHMUK PV P.56489, left palatoquadrate and associated dermal bones in medial view; (b) left operculum and (c) suboperculum of NHMUK P56489 in lateral view. Left nasal of NHMUK PV P.56489 in (d) ventral and (e) dorsal view. (f) Partial skull roof in dorsal view and (g) anterior view of premaxillae of 70.4 .246 (within the NHMUK collections but apparently a WAM catalogue number). Abbreviations: ano=anterior nasal opening; $\mathrm{Fr}=$ frontal (=sarcopterygian parietal); $\mathrm{hpbt}=$ hole for basipterygoid process; $\mathrm{It}=\mathrm{intertemporal}$; $\mathrm{mpl}=\mathrm{middle}$ pit-line; $\mathrm{npl}=$ nasal pit-line; $\mathrm{Pa}=$ parietal (= sarcopterygian postparietal); $\mathrm{ppl}=$ posterior pit-line; spig=spiracular groove; $\mathrm{St}=$ supratemporal; $\mathrm{suc}=$ supraorbital sensory canal.

Posterior to the basipterygoid processes, the parasphenoid is more extensive than that of Mimipiscis toombsi, with a denticulated rectangular median shelf, the posterior margin extending well past the position of the ventral otic fissure. Flanking this shelf on either side is a depressed (in ventral view) flange of smooth endochondral bone. This condition differs from Gogosardina, where the posterior parasphenoid tapers in a diamond-shaped structure (Fig. 14d). Vomerine toothplates like those of Mimipiscis toombsi are not preserved, nor is there evidence of the paired parotic toothplates seen in Moythomasia durgaringa.

\subsection{Lower jaw}

The external dermal surface of the lower jaw consists of a dentary and angular with pre-articular and coronoids on the medial side. As in Cheirolepis (Pearson \& Westoll 1979), Gogosardina (Choo et al. 2009) and Mimipiscis toombsi, there is no surangular. Where present, ornamentation consists of long parallel ridges of ganoine along the ventral and lateral surfaces, with small ridges and tubercles at the dorsal margin and near the anterior tip of the mandible. Near the posterior end of the jaw is a semicircular excavation conforming to the overlapping posteroventral edge of the maxilla. Sections of both the angular and the dentary meet in this region, their surfaces smooth and devoid of ornamentation. The lower jaw of Mimipiscis bartrami is effectively indistinguishable from that of M. toombsi and Gardiner's (1984) description applies equally to both taxa.

\subsection{Operculogular series}

The operculum (Figs 7, 8, 11) is a large diamond-shaped bone, roughly twice the size of the suboperculum. The ventral margin is distinctly convex and overlaps the dorsal margin of the suboperculum, while the anterior margin contacts the dermohyal. Ornament of both the operculum and suboperculum consists of medium to long linear ridges with a predominantly posterolateral orientation.

The suboperculum (Figs 6, 7, 8, 11) is roughly rectangular, with a concave dorsal margin that is devoid of ornamentation where overlain by the opercular. There is a pronounced, anterodorsal process, similar to that present on Howqualepis (Long 1988) and Gogosardina (Choo et al. 2009). It is comparatively longer than the pointed anterodorsal corner present on M. toombsi (Gardiner 1984, fig. 97). Isolated sensory pits are present near the dorsal and posterior margins at midlength along the bone. 


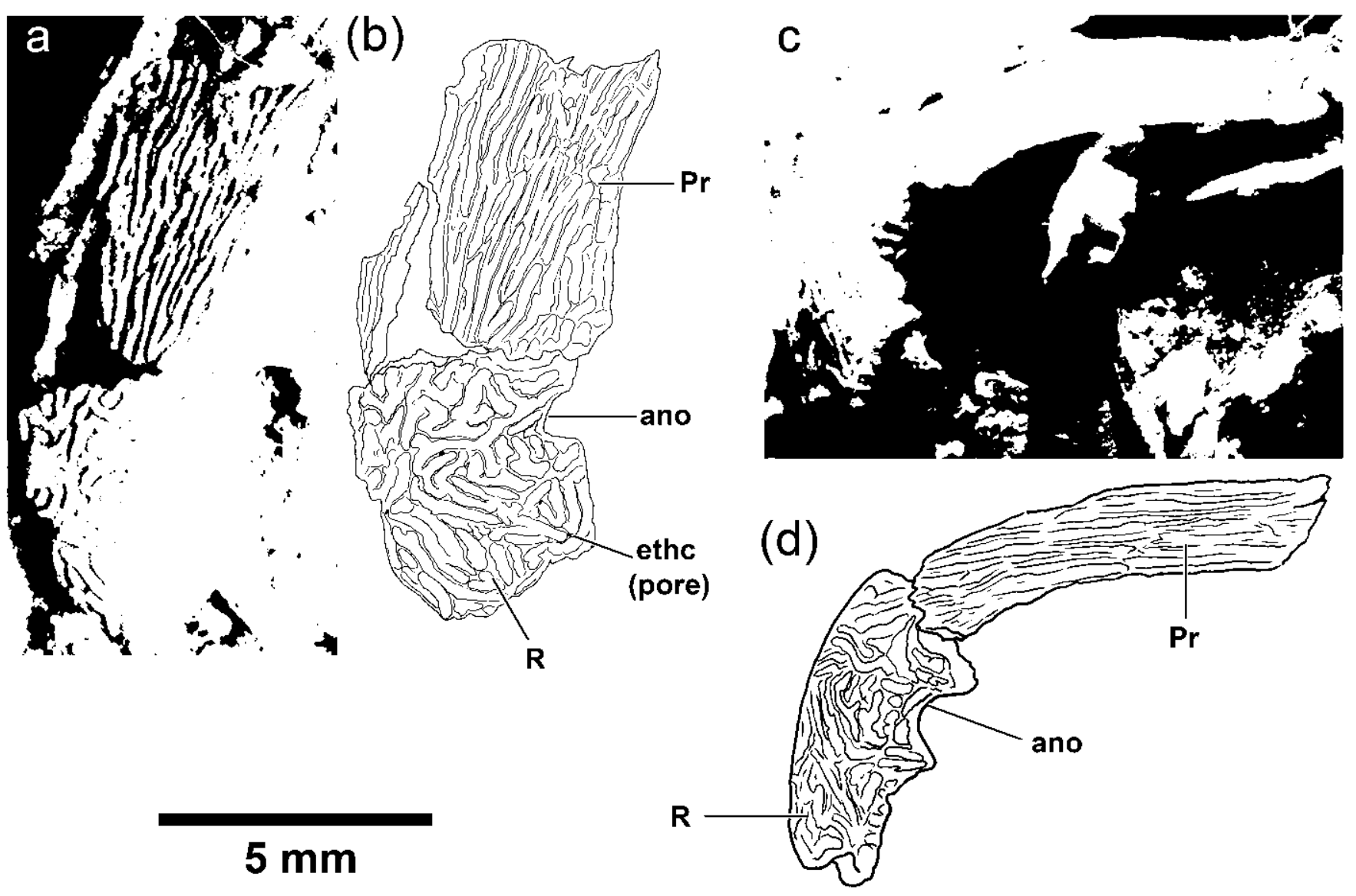

Figure 12 Mimipiscis bartrami sp. nov.: (a) photograph and (b) interpretive drawing of rostral and postrostral of MV P.228270 in anterodorsal view. The bones have been flattened into a single plane. (c) Photograph and (d) interpretive drawing of the same pair of bones in left lateral view. Abbreviations: ano=anterior nasal opening; ethc = pit opening of ethmoidal commissure; $\mathrm{Pr}=$ postrostral; $\mathrm{R}=$ rostral .

More than nine branchiostegal rays are present (Figs 5, 8). They are similar in form and ornamentation to those of $M$. toombsi (Gardiner 1984, fig. 97). The gulars consist of paired lateral units that are much larger than the adjacent branchiostegal rays, flanking a much smaller median gular (Fig. 8).

\subsection{Pectoral girdle}

The posttemporal (Figs 7,8) is a four-sided rectangular bone that tapers slightly inwards towards a narrow median suture with its counterpart. There is a narrow unornamented anterolateral overlap surface for the extrascapular. The main lateral line canal passes through bone near the anterolateral corner. Ornamentation consists of curved linear ridges. It differs from the more narrow posttemporal of M. toombsi (Gardiner 1984, fig. 125) in that the rostrocaudal length is similar to the width while that of $M$. toombsi is almost twice as wide as it is long.

The presupracleithrum (Fig. 7) is a small triangular bone wedged between the posterodorsal corner of the operculum, the anterolateral corner of the posttemporal and the anterodorsal corner of the supracleithrum. Ornament consists of short linear ridges that run parallel to the nearest margin of the bone.

The supracleithrum (Fig. 7) is a long, slender bone with a straight posterior margin. It broadens dorsally where it is overlapped by the posttemporal. The main lateral line canal enters from the dorsal margin via the posttemporal and posteroventrally, exiting approximately two-thirds the way down the posterior margin. Ornamentation consists of posteroventrally directed linear ridges with shorter, circular ridges at the anterior margin.
The postcleithrum (Gardiner 1984, fig. 127A, as Mimia toombsi) is a small sliver-like bone situated behind the pectoral girdle. It is similar in form to that of Mimipiscis toombsi but, as the adjacent flank scales are of a similar size, it is difficult to discern when in articulation.

The cleithrum (Figs 6,9) is a large bone with a tall vertical blade and a strongly concave anterior margin. The posterior margin is strongly convex, with a deep embayment for insertion of the pectoral fin. At the level of this embayment, the ventral region of the bone sharply curves medially. There is a prominent smooth overlap surface on the anterior margin for the clavicle. Ornamentation is complex, with vertically directed ridges near the dorsal apex and anterior margin of the vertical blade, grading into circular patterns near the posterior margin. At the level of the pectoral embayment, thicker ridges run posteroventrally, with rostrocaudally directed ridges on the ventral surface.

The clavicle (Figs 6, 7,9) is large and semiconical, with the posterior margin wrapping around the cleithrum. The bone has distinct vertical and ventral laminae, separated by sharp, medially directed curvature. The vertical face is triangular in profile, with a tall ascending process, while the ventral lamina is broad and flat, coming into close proximity of its opposite counterpart. Ornament consists of rostrocaudally directed wavy ridges. There is a space for a small interclavicle, but such a bone has not been identified in the available material.

\subsection{Body form and fins}

The holotype measures approximately $9 \cdot 5 \mathrm{~cm}$ from the snout to the base of the caudal fin, with the head occupying a little 


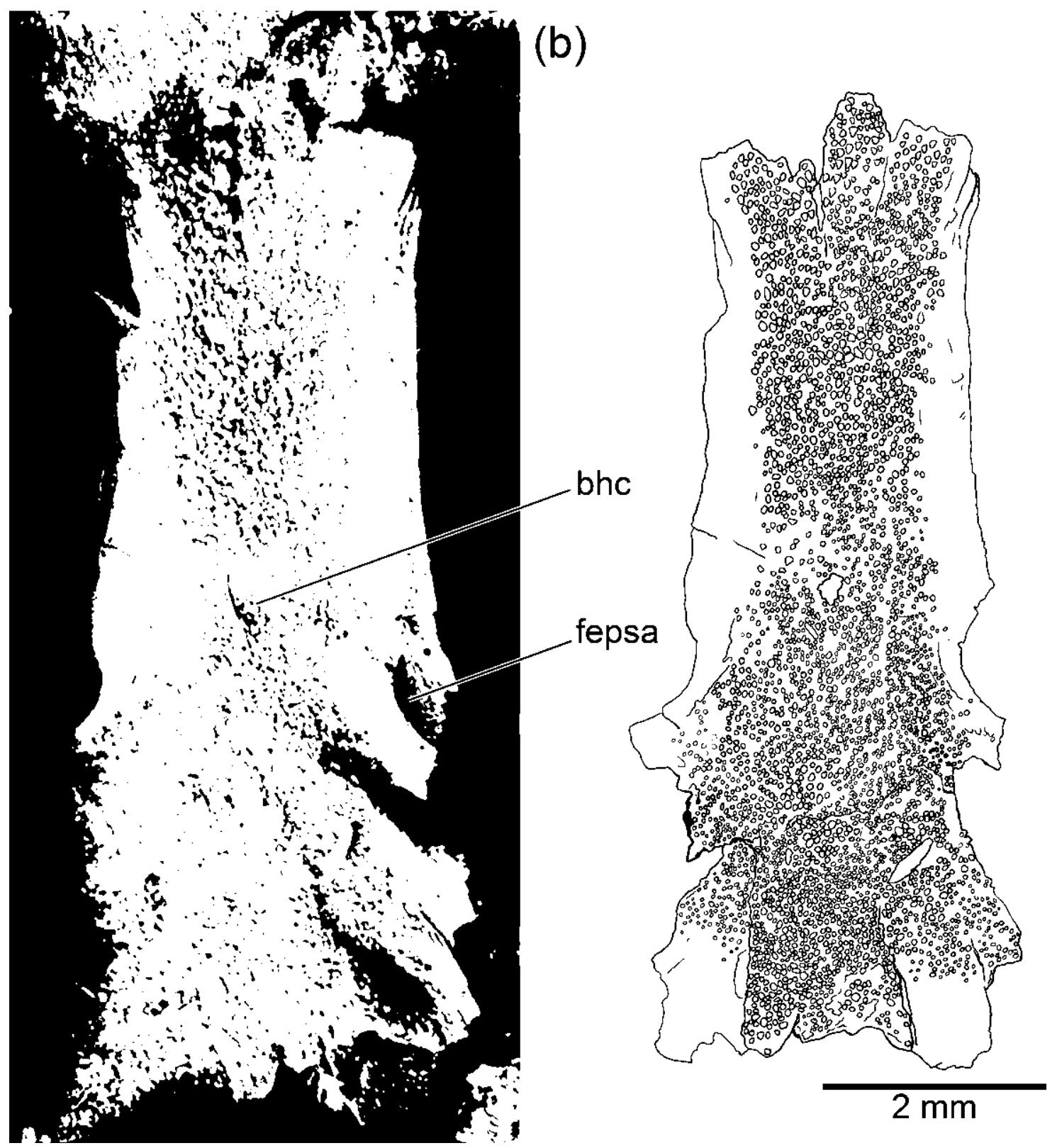

Figure 13 Mimipiscis bartrami sp. nov. (a) photograph of the parasphenoid of the holotype counterpart (WAM 08.9.1b) in ventral view. The posterior section of the bone is broken and rotated counterclockwise. (b) Reconstruction of the parasphenoid with the posterior section realigned. Grey areas represent missing areas. Abbreviations: bhc= bucco-hypophysial canal; fepsa=foramen of efferent pseudobranchial artery.

under one third of this length (Figs 5, 6). MV P.227027 is less complete but represents the largest known specimen with a probable original length of roughly $13 \mathrm{~cm}$ (Figs 8, 9). The body form is stout and fusiform, being about three times as long as it is deep. Near-complete fish that are preserved in lateral view display a distinct hunch-backed profile that is absent or less pronounced in similarly positioned specimens of $M$. toombsi (Figs 5, 10). This suggests that $M$. bartrami was either wider bodied than its congener (appearing deeper due to postmortem lateral compression) or that it possessed a steep dorsal contour that arched dorsally from the back of the skull. The latter interpretation is presented in the lateral reconstruction (Fig. 19).

The pectoral fins (Figs 8, 9, 15) have large unsegmented proximal sections that are better preserved than the remainder of the fin. Small fringing fulcra are present along the leading edge. More than 24 primary lepidotrichia are visible on available specimens. The longest anterior fin rays display segmentation and terminal branching on the distal $40-60 \%$ of their length. Small, lepidotrichial segments suggest the presence of additional, more extensively segmented posterior rays. Disarticulated endoskeletal radials are present including a large, perforated propterygium on MV P.227027 (Fig. 15).

Small, short-based pelvic fins are present approximately $45 \%$ posterior from the pectoral girdle to the start of the caudal fin (Fig. 5). At least 18 lepidotrichia were present. The dorsal fin (Fig. 10b) is triangular and situated in the posterior half of the body. There are more than 30 segmented lepidotrichia, and the leading edge contains fringing fulcra that alternate with lepidotrichial tips.

The anal fin is poorly preserved on available specimens. While it is impossible to determine the shape of the fin, the distribution of the broken fin rays and the ventral scutes reveal the front edge of the fin to be at a point posterior to the leading edge of the dorsal fin (Fig. 10a), as also seen in Krasnoyarichthys (Prokofiev 2002) and Stegotrachelus (Swartz 2009). This differs from the condition in M. toombsi (Fig. 19), where the anterior edges of the median fins are directly opposite one 
(a)
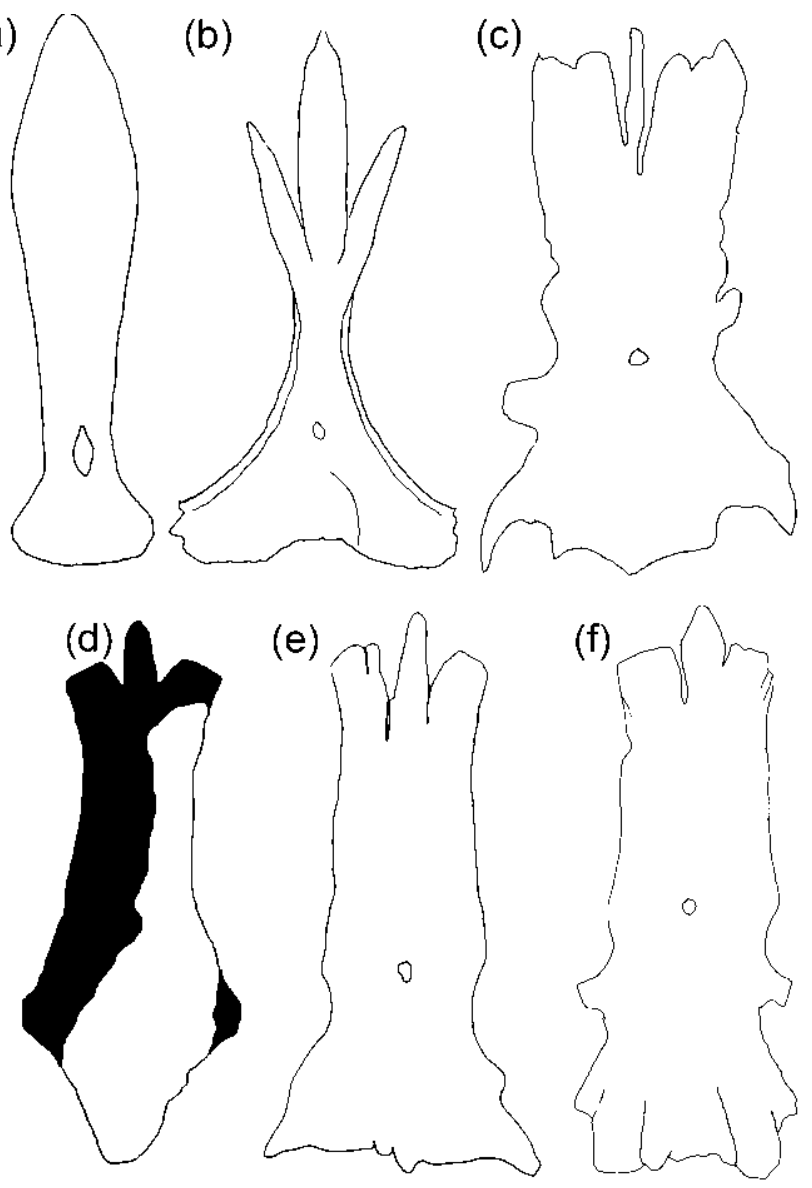

Figure 14 Comparisons of the parasphenoids of Devonian actinopterygians depicted in ventral view. Grey areas correspond to denticulated regions: (a) Cheirolepis trailli (after Pearson \& Westoll 1979); (b) Howqualepis rostridens (after Long 1988); (c) Moythomasia durgaringa (after Gardiner 1984); (d) Gogosardina coatesi (new reconstruction based on WAM 07.12.2 as figured in Choo et al. 2009, fig. 9. Missing areas in black); (e) Mimipiscis toombsi; (f) Mimipiscis bartrami sp. nov. Not drawn to scale.

another. Of the caudal fin, only the anteriormost section of the lower hypochordal lobe is visible on the holotype (Fig. 5), comprising about a dozen rays. Fringing fulcra are preserved on the leading edge.

\subsection{Squamation}

The entire body is clad in rhombic scales with ganoine ornamentation. They are arranged in transverse rows up to the line of inversion on the base of the tail, with no anteromesial redirection on the underside as in Moythomasia nitida (Jessen 1973) and Howqualepis (Long 1988). There are over 110 vertical scale rows between the cleithrum and the caudal inversion, in contrast to ca. 75 scale rows on Mimipiscis toombsi (Gardiner 1984). As in Gogosardina (Choo et al. 2009), the scales undergo several abrupt reductions in size (with a corresponding increase in numbers within each vertical row) along the length of the fish. The ganoine ridges bear only a few isolated raised striae, unlike the prominent ridging present on the scales of Mimipiscis toombsi (Trinajstic 1999b).

6.9.1. Area A. (Fig. 17a, b, f) Scales are narrow and rectangular, with a height to length $(\mathrm{h} / \mathrm{l})$ ratio ranging from more than $4: 1$ in the anterior scales to $3: 1$ in examples near area $\mathrm{B}$. The anterior margin is gently concave in first row scales near the postcleithrum, straight in the remainder. The rostrodorsal process is low and pointed, while the peg is high with a rounded apex. In anterior scales (Fig. 17a), the peg and rostrodorsal process are widely separated from the free field via a depressed dorsal extension that accounts for $40 \%$ of the vertical height of the scale. Anterior scales may also have an anteroventral extension which may either be smooth and depressed or bear a ventrally directed ganoine ridge. Keel and socket are well developed. The depressed field is narrow in first row scales and widens to $30-50 \%$ of scale-length in more posteriorly positioned scales. Ornamentation consists of anastomosing, narrow ganoine ridges that terminate in up to eight posterior serrations on the caudal margin. Each ridge is smooth and devoid of accessory striations. There is a decrease in depth and ornament of the scales near area B, with a reduction in the number of posterior serrations.

6.9.2. Area B. (Fig. 17c, g) Scales are rectangular in shape, with $\mathrm{h} / \mathrm{l}$ ratio varying from $2: 1$ for scales close to area $\mathrm{E}$ to 2.5:1 for mid-flank scales. Rostro-dorsal process, keel, peg and socket are well developed. The peg is high with a rounded apex. The depressed field accounts for about $20-25 \%$ of the scale-length. Ornament consists of 5-7 separate ganoine ridges that terminate in acutely pointed denticles.

6.9.3. Area C. (Fig. 17h, i) There is an abrupt reduction in scale size from area B to C, with flank scales at the level of the dorsal and anal fins being about 1/5 the size of scales at the same vertical level anterior to the dorsal fin. Scales are longer than tall, with an $\mathrm{h} / \mathrm{l}$ ratio of $1: 1 \cdot 5$. Rostro-dorsal process is absent or weakly developed. Anterior and ventral margins are straight. Peg is short and wide based while the keel is well developed. Depressed field is $25 \%$ the length of the scale. Free field ornamentation is similar to area B scales, but with the number of ridges reduced to $3-4$.

6.9.4. Area D. (Fig. 17j) Area D scales are rhombic in shape, becoming increasingly elongate towards the caudal fin. Ganoine ridges reduced to two in scales close to area $\mathrm{C}$, and a single ridge close to the caudal fin. Pegs, sockets and keels greatly reduced or absent. Depressed field is narrow. Squamation from the notochordal mass of the caudal fin has not been preserved.

6.9.5. Area E. (Fig. 17d, k, 1) There is much variability in scale size and shape within the dorsal surface between the head and dorsal fin. Anterior scales have an $\mathrm{h} / 1$ ratio of 2:1, with a wide depressed field accounting for at least $25 \%$ of scale length. Rostro-dorsal process is high and is of equal height to the scale body in the anterior-most examples. The peg, socket and keel are well developed. Each scale has 4-7 separate ridges which may either protrude as caudal denticles or terminate before the caudal margin. From the middle to the rear of area E, the scales are tall and narrow with an $\mathrm{h} / 1$ ration of 5:1. Peg, socket and rostro-dorsal process are greatly reduced or absent. Depressed field is narrow and nearly the entire lateral surface of the scale is ornamented. Ornamentation consists of anastomosing ganoine ridges that terminate before reaching the caudal margin on the dorsal half of the scale and protrude as posterior serrations on the lower half.

6.9.6. Area F. (Fig. 17e) Scales are rostrocaudally elongate, with $\mathrm{h} / 1$ ratio ranging from $1: 2$ to $1: 3$. Peg, socket and keel are poorly developed, while the rostro-dorsal process is high. There are two to three separate ridges with one or two posterior serrations which extend beyond the body of the scale.

6.9.7. Areas $\mathbf{G}$ and $\mathbf{H}$. Scales in these areas are either not preserved or poorly exposed on available specimens. Scales are rhombic in shape with two separate ganoine ridges which taper to posterior points usually not protruding past the scale-body. No pegs or sockets are visible.

6.9.8. Ridge scutes. (Fig. 17m) Median scutes are present on both the dorsal and ventral surface. Dorsal scutes are overlapping disc-shaped structures, becoming narrow at the base of the dorsal fin, with about ten longitudinal ridges on their surfaces. Each is over ten times larger than the adjacent 


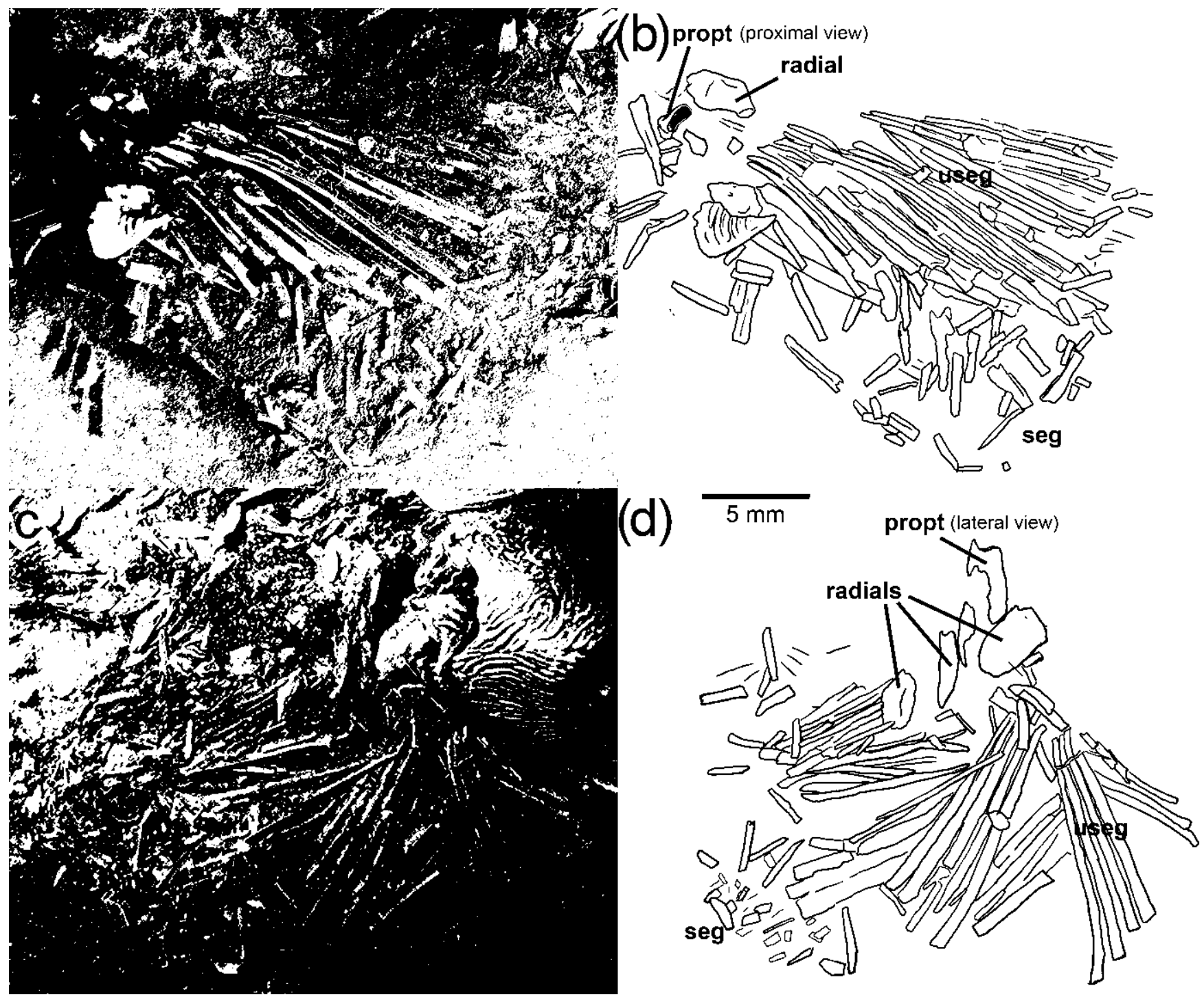

Figure 15 Mimipiscis bartrami sp. nov. Pectoral fins of MV P.227027: (a) photograph and (b) interpretive drawing of the left pectoral fin of MV P.227027a in lateral view; (c) photograph and (d) interpretive drawing of the right pectoral fin of MV P.227027b in lateral view. Abbreviations: propt=propterygium; seg=segmented distal lepidotrichia; useg $=$ unsegmented proximal lepidotrichia.

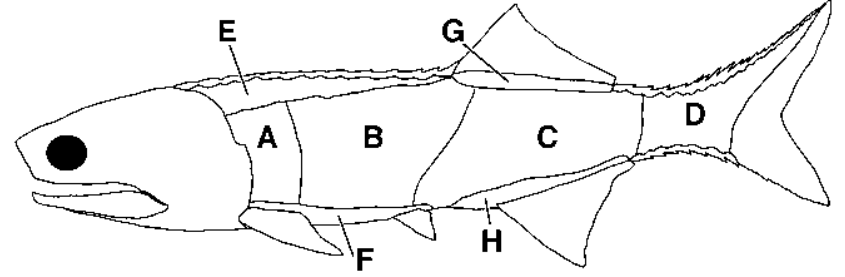

Figure 16 Diagrammatic outline of a mimiid actinopterygian based on Gogosardina coatesi (Choo, Long \& Trinajstic, 2009), detailing distribution of major areas of morphologically distinct scale types as erected by Esin (1990).

dorsal scales. A complete series is not preserved, but given their size, there would have been $18-20$ originally present between the dorsal fin and supratemporals. There are two large ventral scutes anterior to the anal fin and at least six between the caudal and anal fins.

\section{Discussion}

\subsection{Diversity and lifestyle}

Until recently, the Gogo actinopterygian diversity of only two taxa (Mimipiscis toombsi and Moythomasia durgaringa) has indicated a low diversity of ray-finned fish within that fossil fauna. Recent research has revealed at least three additional forms of ray-finned fish in the Gogo assemblage: Mimipiscis bartrami, Gogosardina coatesi (Choo et al. 2009) and an additional undescribed form that represents a new genus and species (pers. observation). This represents the greatest number of ray-finned species within a single Devonian fossil-bearing formation.

Fossil evidence suggests that Gogo actinopterygians preyed on conodont animals, at least on occasion. Two specimens, one from Mimipiscis bartrami and the other from Gogosardina coatesi, are notable in the preservation of conodont elements within the body cavity. Nicoll (1977) described a partially prepared palaeoniscoid specimen (Fig. 10a, subsequently redesignated as ANU V1824) that contained the remains of two separate conodont animals within its gut cavity. The complete, 15-element apparatus of Oulodus angulatus and a partial apparatus (13 elements) of Icriodus brevis were visible. Recent examination of the specimen at ANU has confirmed that the fish is a specimen of $M$. bartrami based on squamation and body shape.

The Gogosardina specimen (MV P.228849) contains the partial apparatus of a single hibbardellid conodont animal 

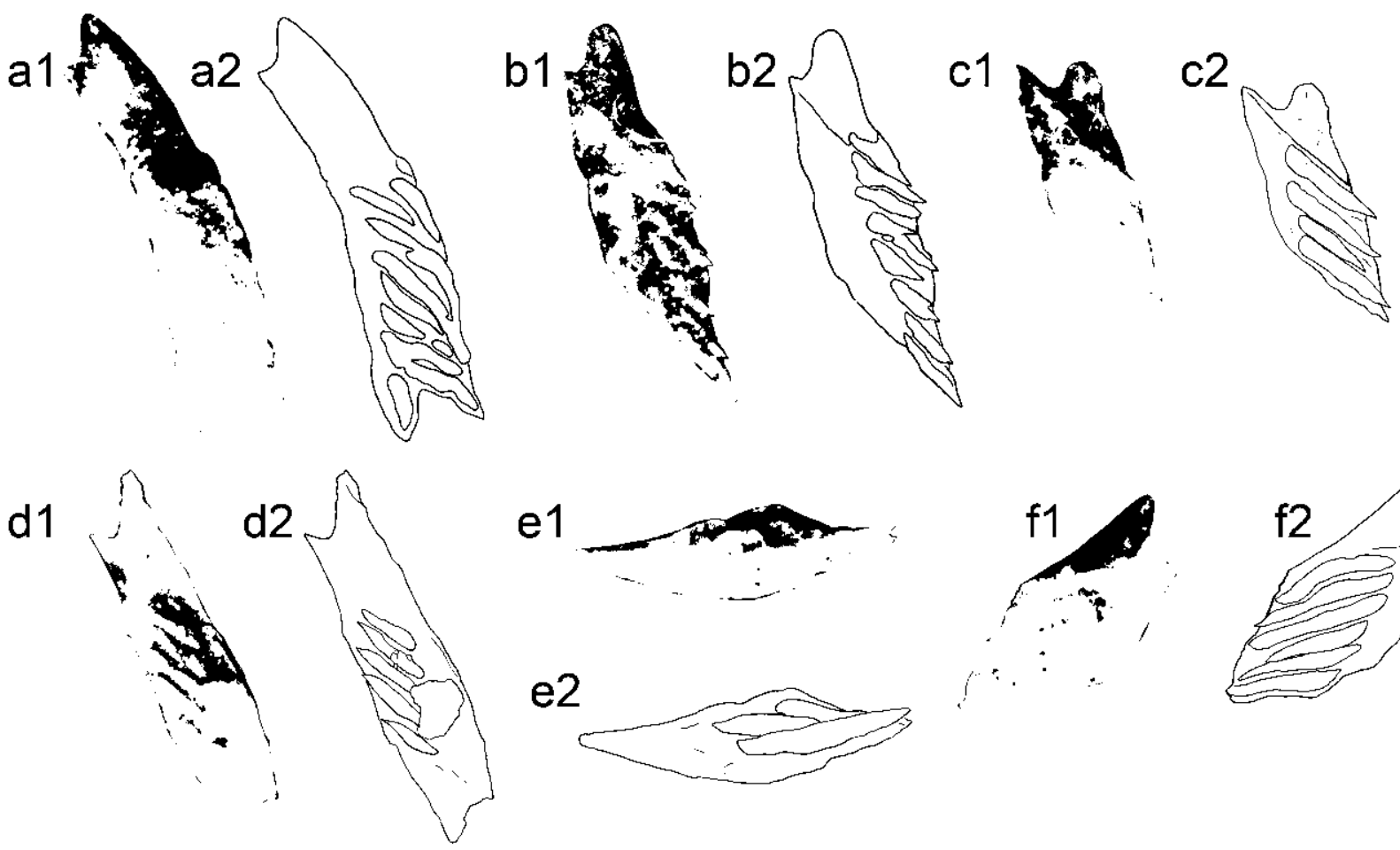

e1
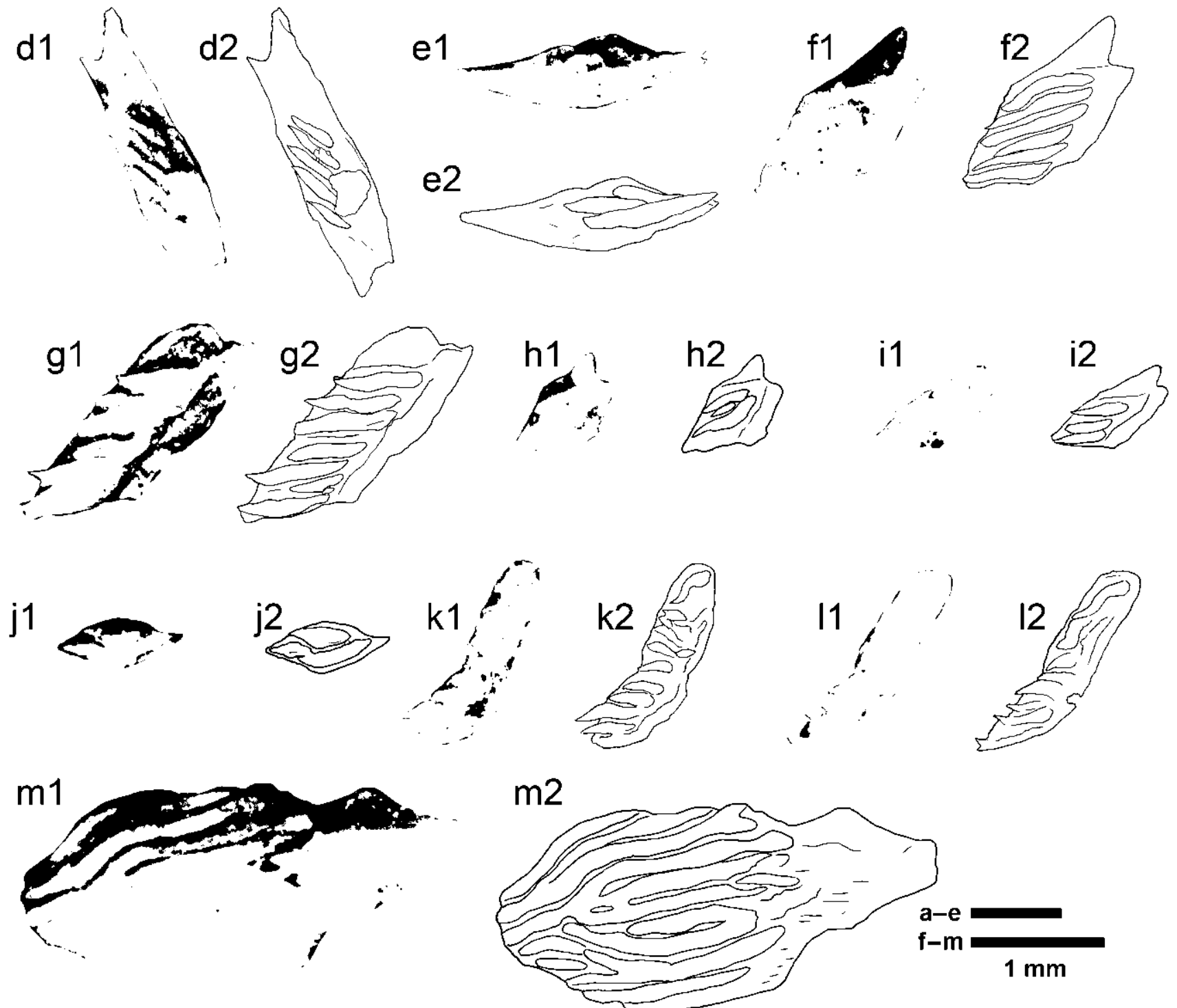

Figure 17 Body squamation of Mimipiscis bartrami sp. nov. Each individual scale is depicted as a photograph (letter+1) accompanied by an interpretative drawing (letter+2). (a-e) Scales from the left side of MV P.227027a: (a) first row scale from the anterior region of area $\mathrm{A}$; (b) scale from posterior region of area $\mathrm{A}$; (c) scale from anterior of area B, near transition zone with area E; (d) scale from anterior of area E; (e) scale from area F. (f-m) Scales from the right side and dorsal region of the holotype (WAM 08.9.1a): (f) scale from area A near transition zone with area E; (g) posterior area B scale; (h, i) area C scales; (j) scale from anterior of area D; (k, l) scales from the posterior of area $\mathrm{E}$, close to the anterior margin of the dorsal fin; $(\mathrm{m})$ median dorsal scute, anterior of the dorsal fin. Areas A-F as shown in Figure 16.

among the branchial elements (Choo et al. 2009). Unlike the Mimipiscis, which successfully ingested two entire conodont animals prior to death, this unfortunate fish appears to have expired after unsuccessfully trying to swallow or expel an oversized prey item.
7.2. Relative abundance of the Gogo actinopterygians It is difficult to determine the relative abundance of the different Gogo actinopterygian species (or any other Gogo taxon for that matter), as specimens are spread across multiple institutions and many collected nodules remain unprepared. 

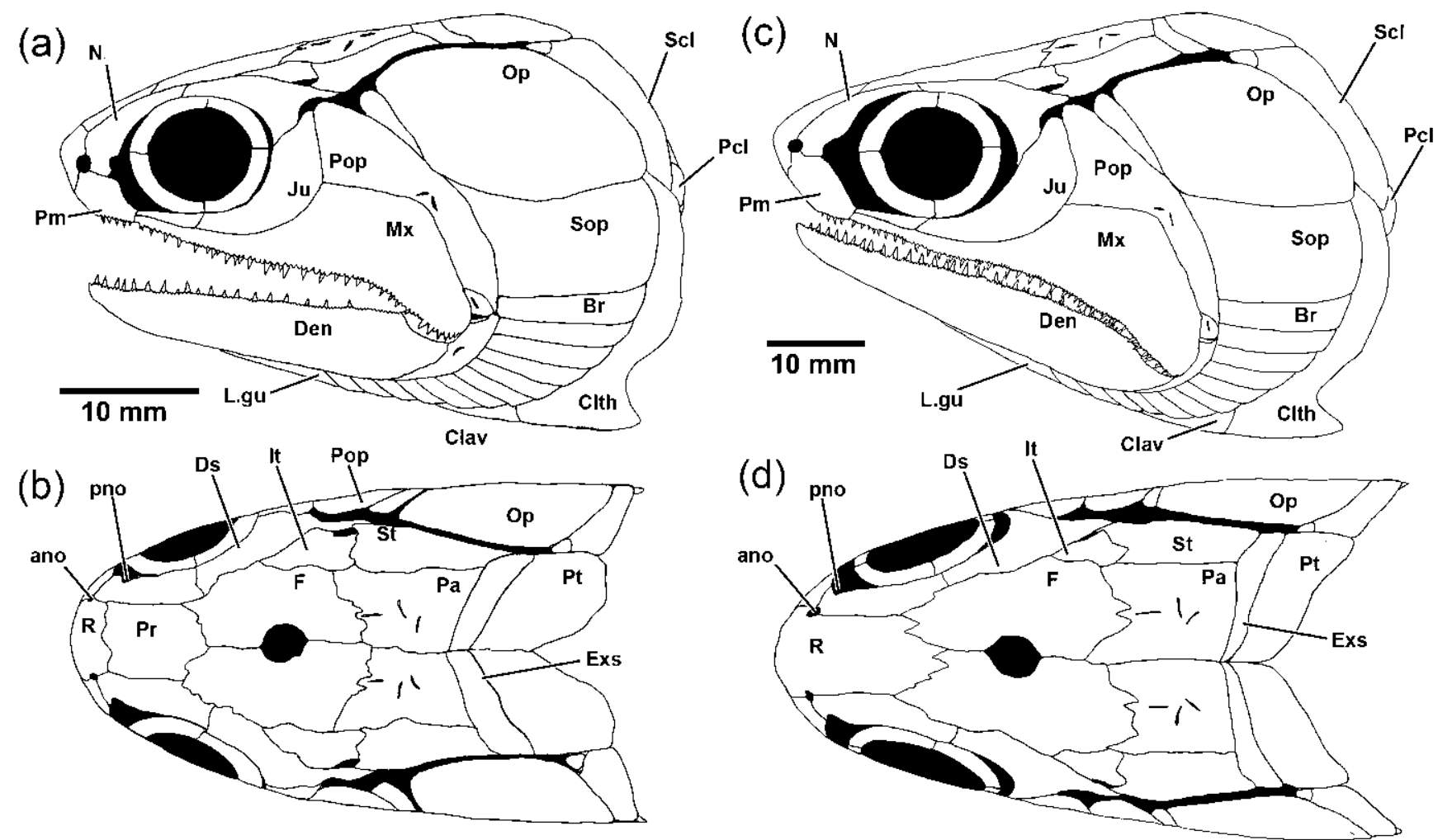

Figure 18 Skull reconstructions of Mimipiscis spp. Skull reconstruction of Mimipiscis bartrami sp. nov. in (a) lateral and (b) dorsal view. Skull reconstruction of Mimipiscis toombsi in (c) lateral and (d) dorsal view. Adjacent $10 \mathrm{~mm}$ scale bars based on the largest known specimen of each species. Abbreviations: ano=anterior nasal opening; $\mathrm{Br}=$ branchiostegal rays; Clav=clavicle; $\mathrm{Clth}=$ cleithrum; Den=dentary; $\mathrm{Ds}=$ dermosphenotic; Exs = extrascapular; $\mathrm{F}=$ frontal; $\mathrm{It}=$ intertemporal; Ju=jugal; L.gu=lateral gular; $\mathrm{Mx}=$ maxilla; $\mathrm{N}=$ nasal; $\mathrm{Op}=$ operculum; $\mathrm{Pa}=$ parietal; $\mathrm{Pcl}=$ postcleithrum; $\mathrm{Pm}=$ premaxilla; $\mathrm{pno}=$ posterior nasal opening; $\mathrm{Pop}=$ preoperculum; $\mathrm{Pr}=$ postrostral; $\mathrm{Pt}=$ posttemporal; $\mathrm{R}=$ rostral; $\mathrm{Scl}=$ supracleithrum; $\mathrm{Sop}=$ suboperculum; $\mathrm{St}=$ supratemporal .

The largest single collection of fully prepared Gogo actinopterygians is housed at the Natural History Museum, London.

Including the holotype specimens of Moythomasia durgaringa and Mimipiscis toombsi that were returned to the Western Australian Museum, and not including a small number of unprepared specimens, the collection comprises 95 individuals that represent four out of the five known taxa in the following numbers (with all taxa except Moythomasia catalogued as 'Mimia toombsi'):

\section{Moythomasia durgaringa $=33$ \\ Mimipiscis toombsi $=52$ \\ Mimipiscis bartrami $=9$ \\ Gogosardina coatesi $=1$}

In this limited sample, Moythomasia durgaringa and Mimipiscis toombsi are by far the most abundant ray-finned taxa in the assemblage. However $M$. bartrami is by no means rare, accounting for about one in six Mimipiscis specimens examined. Given that the two species of Mimipiscis were combined in the previous descriptive literature, it is fortunate that an example of the more abundant, larger-scaled form was selected as the type specimen. The remaining two Gogo genera are rarities, with Gogosardina known from a total of five specimens (one NHMUK, one WAM and three MV specimens) and an additional undescribed genus known from a single fossil in the WAM collections.

\subsection{Phylogenetic analysis}

Research into early actinopterygian phylogeny has been summarised in Swartz (2009). While Devonian actinopterygians are incorporated into numerous studies (eg. Patterson 1982;
Gardiner 1984; Gardiner \& Schaeffer 1989; Coates 1998, 1999; Lund 2000; Lund \& Poplin 2002), many of these are primarily concerned with the position of early taxa relative to postPalaeozoic forms. Several recent studies have examined the possible interrelationships among early actinopterygians with emphasis on Devonian taxa (Fig. 20).

Taverne (1997) presented a tree of Devonian actinopterygians, plus the extant bichirs, finding Dialipina to be the sister-taxon to the remainder of the Actinopterygii, with the rest of the examined genera forming successive plesions of stem actinopterygians and actinopterans. Schultze \& Cumbaa (2001) coded a selection of Devonian and Carboniferous fossil taxa along with Polypterus that produced nine equally parsimonious trees, a strict consensus of which again found Dialpina to be the basal taxon of the Actinopterygii, followed by Polypterus, Tegeolepis, Cheirolepis, Osorioichthys, with poor resolution in the remainder of the tree.

Friedman \& Blom (2006) presented a consensus of four trees (with the problematic Dialipina omitted from the primary analysis), placing Cheirolepis in the basal position among actinopterygians, followed by Osorioichthys. A clade containing Tegeolepis and Howqualepis was resolved above Osorioichthys, united by long, unsegmented pectoral lepidotrichia and enlarged parasymphysial teeth on the reflexed anterior dentary. Above this novel clade is a large assemblage, with Mimipiscis toombsi resolved as the sister taxon of a large assemblage consisting of Kentuckia, two short-bodied Euramerican forms (Cuneognathus and Limnomis) and a variety of 'Stegotrachelus-grade' taxa.

The Friedman \& Blom (2006) study provided the framework for two subsequent analyses. The analysis of Long et al. (2008) added Cheirolepis schultzei, Donnrosenia schaefferi and 

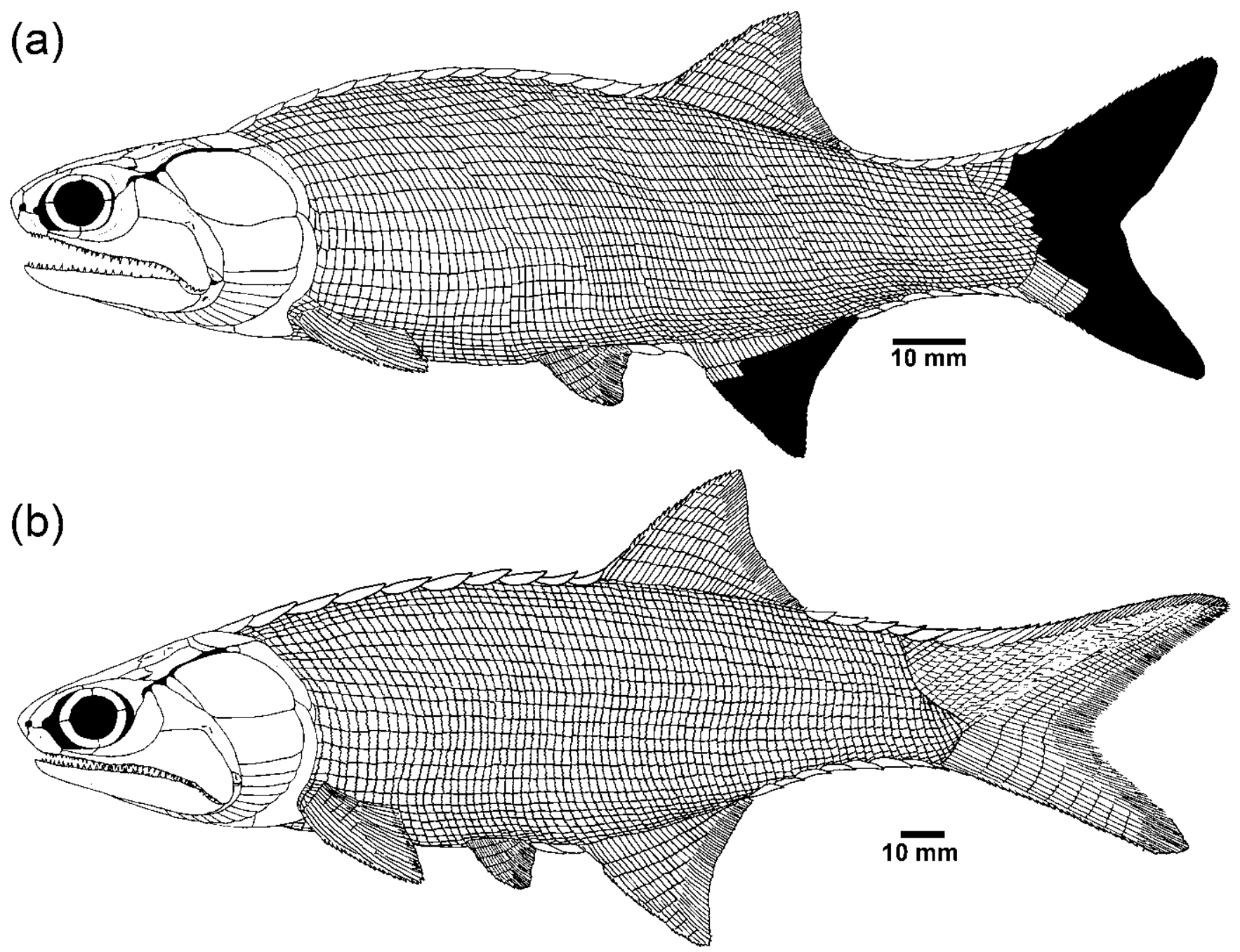

Figure 19 Full-body reconstructions of (a) Mimipiscis bartrami sp. nov. and (b) Mimipiscis toombsi (modified from Gardiner 1984) in left lateral view. Dark grey areas correspond to missing areas of the anal and caudal fin. $10 \mathrm{~mm}$ scale bars adjacent to each reconstruction indicate the size of the largest known specimens of each species.

Mimipiscis bartrami (='Mimia' sp. nov), achieving poor resolution above Cheirolepis and the sister-pairing of certain taxa (for example, the two 'Mimia' species). Donnrosenia was resolved as the sister taxon to Howqualepis (in the newly formed clade Howqualepdidae), with Tegeolepis as a more taxon. The two species of Moythomasia examined did not emerge as a monophyletic grouping, with $M$. nitida recovered within 'Stegotrachelus-grade assemblage' (along with Krasnoyarichthys and Stegotrachelus) exclusive to M. durgaringa. The possibility of a regionally endemic Gondwanan radiation of Devonian actinopterygians was suggested.

Swartz (2009) provided thorough redescription and recoding of Stegotrachelus and added three Carboniferous taxa to the previously Devonian-exclusive analysis. The Howqualepididae was rejected, and Friedman \& Bloms' pairing of Howqualepis plus Tegeolepis was reaffirmed. Donnrosenia was resolved as the sister taxon to all the analysed actinopterygians except for Osorioichthys and Cheirolepis. With regards to the Gogo genera, Mimipiscis was paired with Krasnoyarichthys, while Moythomasia (the monophyly of the Australian $M$. durgaringa and the German $M$. nitida is reaffirmed) is linked with Stegotrachelus within a monophyletic Stegotrachelidae.

Although not primarily concerned with Devonian taxa, Cloutier \& Arratia (2004) conducted a comprehensive phylogenetic study that incorporated a wide range of Devonian forms, but produced results notably divergent from other hypotheses of interrelationships. Of the four trees incorporat- ing extant taxa, three placed all Palaeozoic taxa outside the crown-group Actinopterygii, diverging strongly from previous analyses. With regards to Devonian actinopterygians, the only consistently resolved relationships were the monophyly of Cheirolepis and a sister-taxon relationship between Mimipiscis and Moythomasia, to the exclusion of all other Devonian forms.

Attempts to resolve the interrelationships between the basal Actinopterygii encounter numerous hindrances. The rayfinned fishes of the Gogo Formation represent the only Palaeozoic representatives of this group with complete dermal and endochondral preservation. Of the remainder, the majority are based on flattened dermal remains with little or no endochondral preservation. The researcher is left with three less than ideal choices when selecting characters: focus on a handful of well known forms and ignore the great majority of fossil taxa (eg. Gardiner et al. 2005); rely primarily on dermal characters and omit potentially valuable braincase data (eg. Friedman \& Blom 2006; Long et al. 2008; Swartz 2009); or one must accept a vast amount of missing data in constructing the character matrix (eg. Cloutier \& Arratia 2004). At present, detailed information of the braincase of Devonian actinopterygians is limited to Gogo material, and thus is of limited value when applied to a Devonian sample of taxa. Ligulalepis toombsi from the Emsian of New South Wales, material of which includes a partial neurocranium, was initially referred to the Actinopterygii (Schultze 1968; Basden et al. 2000; Basden \& 

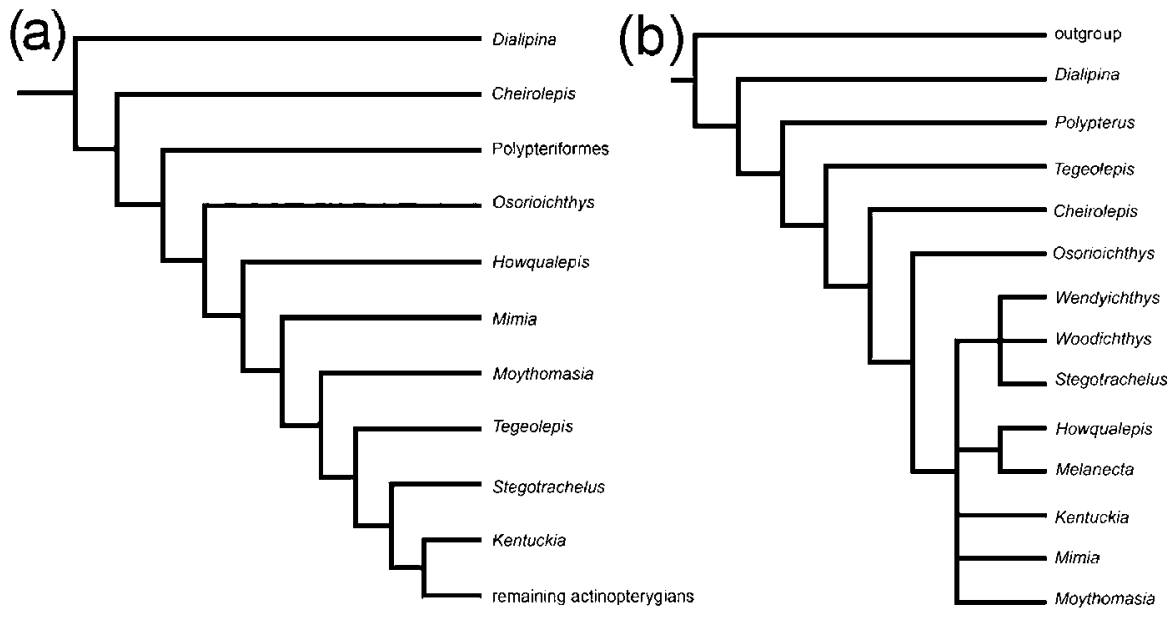

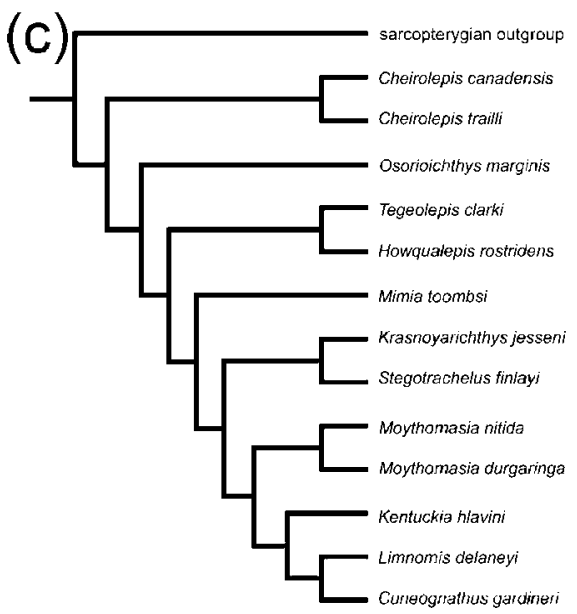

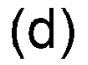

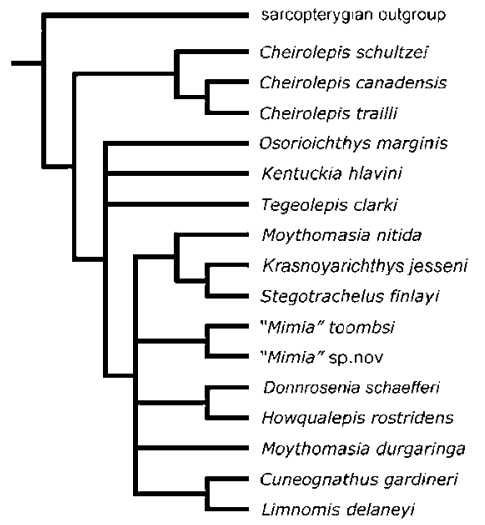

(e)

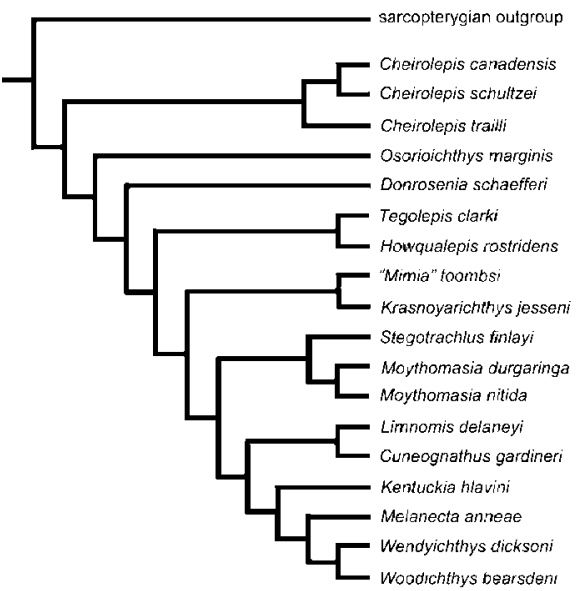

Figure 20 Previous hypotheses regarding the interrelationships of Devonian actinopterygians: (a) Taverne (1997); (b) Schultze \& Cumbaa (2001); (c) Friedman \& Blom (2006); (d) Long et al. (2008); (e) Swartz (2009).

Young 2001), but in subsequent analyses has been resolved as a sarcopterygian (Zhu et al. 2009) or stem-osteichthyan (Botella et al. 2007; Friedman 2007; Brazeau 2009; Friedman \& Brazeau 2010).

It is also certain that a large proportion of the earliest actinopterygian diversity is currently missing from the fossil record. Early sarcopterygians (Guiyu oneiros and additional taxa) are known from the Kuanti Formation of the Late Silurian (Ludlow) of Yunnan, China (Zhu et al. 2009). Although the Sarcopterygii and Actinopterygii must have diverged at some point before this, the earliest articulated actinopterygians date either from the Emsian (if Dialipina salgueiroensis is accepted as an actinopterygian) or the Eifelian-Givetian (if Cheirolepis trailli is accepted as the earliest undisputed actinopterygian) of the Devonian. Recent analyses have resolved the Dialipina salgueroensis from the Emsian of the Canadian Arctic as either an actinopterygian (Schultze \& Cumbaa 2001; Zhu et al. 2009) or as a stemosteichthyan (Friedman 2007; Brazeau 2009; Friedman \& Brazeau 2010).

The excellent preservation of Mimipiscis bartrami and Gogosardina can assist in clarifying the interrelationships of the earliest actinopterygians. The data matrix in the following analysis is largely based on Friedman \& Blom (2006), with additional taxa and characters. The complete taxon-character matrix and apomorphy list are presented in the Appendices. PAUP 4.0b10 for Microsoft Windows was used to perform a heuristic search, with the results processed on Maclade 2.0.

The ingroup comprises 23 taxa, 18 of which represent the totality of undisputed Devonian actinopterygian taxa that are well described in the literature. The outgroup consists of four taxa, comprising three Devonian crown-group sarcopterygians along with Guiyu. It represents the earliest and most primitive osteichthyan known from fairly complete articulated remains (Zhu et al. 2009). Dialipina salgueroensis was omitted from the analysis owing to the complex and unusual facial osteology of this taxon that is difficult to directly compare with the ingroup taxa used in this study using currently published material (Schultze \& Cumbaa 2001).

In addition to both species of Mimipiscis, the analysis includes two other Gogo actinopterygians, Gogosardina coatesi and Moythomasia durgaringa, and is recoded based on direct observation of exceptional specimens collected in 2005 (Choo in prep). The form briefly described by Jessen (1968) as Moythomasia cf. striata from the Frasnian of BergischGladbach, Germany is coded as Moythomasia sp. nov. and will be described in detail in a future publication (Choo in prep).

Five Carboniferous actinopterygians are also in the ingroup. Three of these (Melanecta, Woodichthys and Wendyichthys) were added by Swartz (2009) to his revision of the Friedman \& Blom (2006) analysis, based on the redescription of Stegotrachelus. To further test the influence of the inclusion of post-Devonian taxa, Mansfieldiscus and Novagonatodus of the early Carboniferous of Victoria were included.

The character states regarding fringing fulcra (Friedman \& Blom 2006: character 37) has been simplified to 'absent or present' pending a comprehensive reappraisal of the diversity and form of fulcra in early actinopterygians (G. Arratia, pers. comm. 2008). Cheirolepis, contrary to previous codings (Friedman \& Blom 2006; Long et al. 2008), has been demonstrated to 


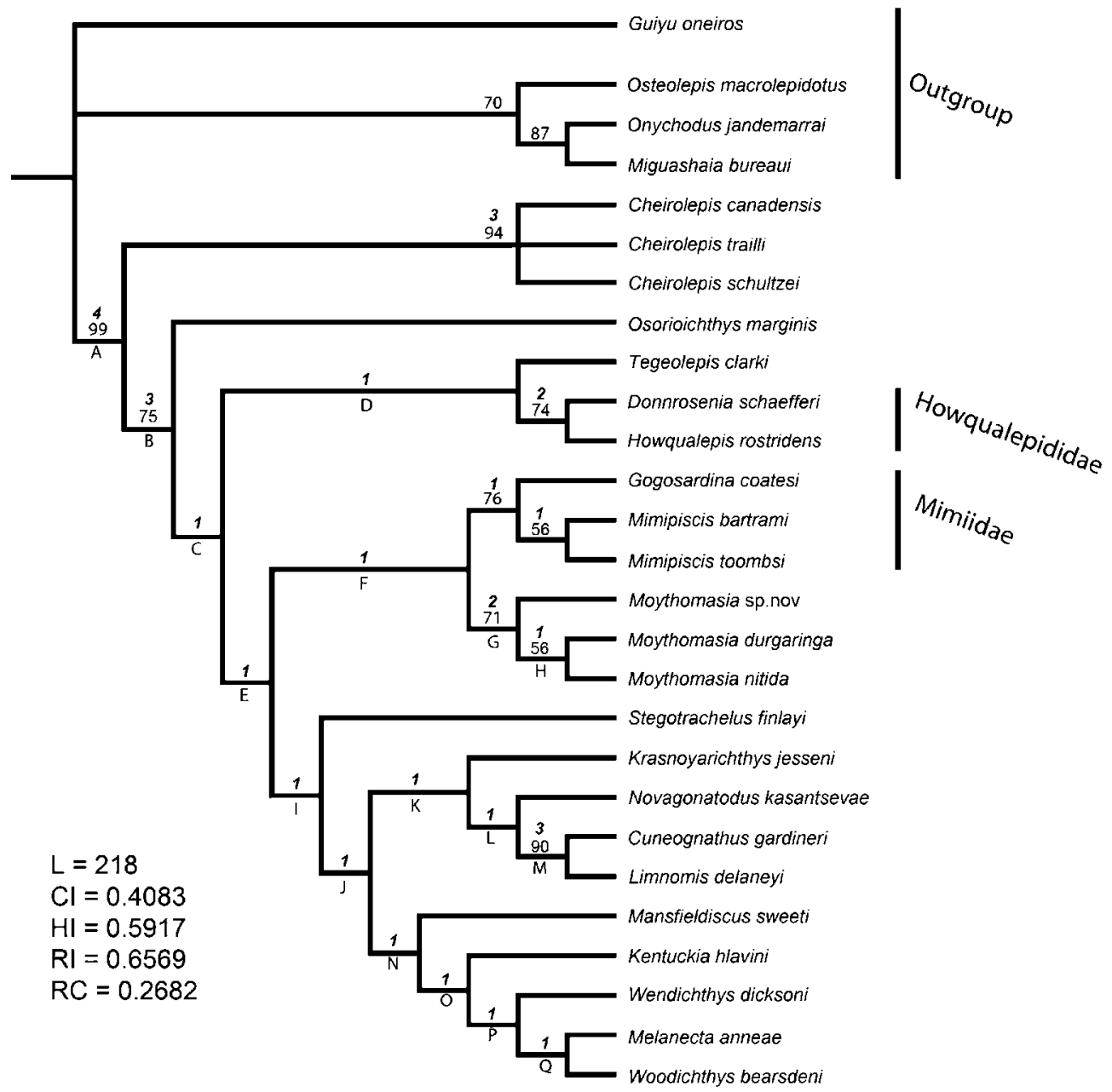

Figure 21 Strict consensus of three most parsimonious cladograms that depict the interrelationships of basal Actinopterygii. Italicised values above nodes represent Bremer decay indices. Where present, non-italicised values above nodes represent bootstrap support values based on 1000 pseudoreplicates. Letters below branches are keyed to the apomorphy list provided in the Appendix.

possess true fringing fulcra (Arratia 2009) and a reappraisal of Howqualepis (Choo 2009) suggests the same applies to this Gondwanan taxon.

The state for character 44 , regarding the segmentation of the pectoral fin, was recoded for Howqualepis. A complete pectoral fin of Howqualepis rostridens was not figured in the original description (Long 1988) and fresh latex peels have revealed extensive posterior segmentation (Choo 2009). Both Howqualepis and Donnrosenia have unsegmented proximal anterior lepidotrichia on the pectoral fin that are longer than in most other examined forms, accounting for more than $60 \%$ of the length of the fin. Tegeolepis is the only Devonian taxon in which all pectoral lepidotrichia have long, unsegmented regions.

A strict consensus of three most parsimonious trees $(218$ steps; consistency index $=0 \cdot 4083$; homoplasy index $=0.5917$, retention index $=0 \cdot 6569$; rescaled consistency index $=0 \cdot 2682$ ) is shown in Figure 21. All three trees resolved a monophyletic Mimiidae, with the Gogosardina forming the sister-taxon to the two species of Mimipiscis, the only variable ingroup feature being an unresolved trichotomy between the three Cheirolepis spp.

The tree forms a basal polytomy between Guiyu, crowngroup sarcopterygians and the Actinopterygii. Within the ingroup, Cheirolepis occupies a basal position among the Actinopterygii, followed by Osorioichthys as outgroups to the remainder of the actinopterygians. A clade consisting of
Tegeolepis plus the Howqualepdidae (Donnrosenia+Howqualepis) is resolved above Osorioichthys, based on the anterior expansion of the lachrymal, lack of mentomeckelian ossification and the relative position of the median fins (of which only the latter character state is known for Donnrosenia). Of the characters previously highlighted as supporting an exclusive union between Howqualepis and Tegeolepis (Friedman \& Blom 2006; Swartz 2009), the absence of pectoral segmentation has been addressed in the restudy of $H$. rostridens mentioned above, while the presence of enlarged parasymphysial teeth in both taxa is resolved as ambiguous in this analysis. Donnrosenia is reaffirmed as the sister-taxon of Howqualepis supported by a bootstrap value of $74 \%$ and based on six unambiguous characters: contact between supratemporal-intertemporal anterior to that of the frontal-parietal; absence of ventral scutes between the caudal and anal fins; long-based pelvic fin insertion, presence of a distinct quadratojugal; operculum more than twice the height of the suboperculum; and a narrow anterodorsal process on the suboperculum and anastomosing scale ornament.

Crownward is a clade containing the Western Australian Mimiidae (Mimipiscis + Gogosardina) and the cosmopolitan Moythomasia (as suggested by Cloutier \& Arratia 2004). The grouping of the mimiids with Moythomasia is, however, weakly supported, based on the tripartite division of the anterior parasphenoid (known only for the Gogo taxa) and the presence of a subopercular anterodorsal process. Contrary 
to Long et al. (2008), the monophyly of Moythomasia is reaffirmed (as in Swartz 2009) with the Gogo Moythomasia durgaringa, displaying a close relationship with the two Bergisch-Gladbach taxa (Moy. nitida and Moy. sp. nov) based on five unambiguous characters: similar lengths of the intertemporal and supratemporal; anterior lachrimal expansion; serrated ornament on the skull roof; the absence of medially directed branching of the sensory canals on the extrascapulae; and dorsoventral expansion of the first branchiostegal ray.

The monophyly of the Mimiidae is unambiguously supported by the absence of both a surangular on the lower jaw and ascending processes on the parasphenoid, with bootstrap support of $76 \%$. Howqualepis, assigned to the Mimiidae by Gardiner (1993), is excluded from this clade. The two Mimipiscis species are resolved closer to one another than to Gogosardina, based on scale ornament (presence of anastomosing ridges) and the lateral rather than posterolateral contact of the intertemporals to the parietals. Additional unpublished data on the braincase of Gogosardina reveals notable differences of the neurocrania to both species of Mimipiscis, and further supports the division of the Mimiidae into two genera.

Stegotrachelus, contrary to Swartz (2009), is not resolved within a monophyletic Stegotrachelidae, but rather as the sister group to all remaining members of a clade containing Krasnoyarichthys, Cuneognathus, Limnomis, Kentuckia and all the examined Carboniferous taxa. The clade is based on three characters, none of which have a consistency index of greater than $40 \%$, and correspondingly has low bootstrap support. Within this group, the only union that is strongly supported is the pairing of the short-bodied Famennian taxa Cuneognathus and Limnomis, based on the absence of pelvic fins and the lack of dorsal pegs on the flank scales. One key character that previously united the two taxa in Friedman and Blom (2006), the presence of curved ridges coursing along the anterior scale margin combined with transverse ridges along the remainder of the scale, is not resolved as a synapomorphy of this particular pairing due to the presence of the feature in the Carboniferous Mansfieldiscus and Novagonatodus (Long 1988).

The position of Krasnoyarichthys, the only form examined with substantial missing cranial data, is problematic and is resolved here at the base of a clade containing Novagonatodus and Cuneognathus + Limnomis. No evidence for the sister-taxon relationship of this Siberian form with Mimipiscis as presented by Swartz (2009) was produced. The clade resolved by Swartz containing Kentuckia and the Carboniferous Melanecta, Wendichthys and Woodichthys is maintained, with Mansfieldiscus included as the most basal member.

The preliminary analysis presented by Long et al. (2008) suggested the possibility of an exclusive, primarily Gondwanan radiation containing all the Gogo taxa, the Howqualepididae and (Limnomis + Cuneognathus). This concept is not supported in the current analysis. However, the analysis does still suggest a limited degree of regional endemism within the Devonian of Gondwana, with the Mimiidae restricted to marine deposits of Frasnian Western Australia and the Howqualepididae restricted to Givetian freshwater deposits of Eastern Gondwana. The Gogo Moythomasia durgaringa does, however, appear to be representative of a wide-ranging Late Devonian genus.

The presence of a surangular on Moythomasia and the Howqualepididae suggests that the absence of this feature within the Actinopterygii crownward of Cheirolepis is a derived state of the Mimiidae. Gardiner (1984) considered Moythomasia durgaringa to be more advanced than Mimipiscis due to the latter lacking ascending processes on the parasphenoid, a feature shared with Cheirolepis trailli. However, the presence of ascending processes in Howqualepis and Tegeolepis suggests that their absence in Mimipiscis is the result of a derived loss of these structures rather than a retained primitive feature.

\section{Acknowledgments}

Many thanks are due to my supervisors, John Long and Gavin Young, for their invaluable guidance. Useful information was provided by Kate Trinajstic, Tim Holland, Erich Fitzgerald, Brian Swartz and Gloria Arratia. David Pickering is commended for his outstanding preparatory skills, as is Lucinda Gibson for her photography of the squamation. Zerina Johanson and Martha Richter provided access to the specimens in the NHMUK collections. Professor Brian Gardiner is thanked for his helpful comments and encouragement. Many thanks to Vicki Hammond, Andrew Smith and two anonymous reviewers for improving the manuscript. This work was supported by an Australian Research Council Discovery Project DP0558499, and is a contribution to IGCP Project 491.

\section{Appendices}

\subsection{Appendix 1: Character list}

Character list used in phylogenetic analysis. Multistate characters marked with an asterisk are ordered. Characters are based on those presented in Friedman \& Blom 2006, except where stated otherwise.

1. Rostral (or equivalent ethmoid bone) - contributes to biting margin. $0=$ absent; $1=$ present.

2. Premaxillae - shape of. $0=$ wider than deep; $1=$ depth approximately equal to width.

3. Postrostrals. $0=$ absent; $1=$ present.

4. Single median rostral, contacting nasals laterally, frontals/ postrostrals posteriorly: $0=$ absent; $1=$ present.

5. Rostral (or equivalent ethmoid bone) with transverse ornamentation: $0=$ absent; $1=$ present.

6. Posterior nostril-communication with orbital fenestra: $0=$ absent; 1 = present.

7. Posterior nostril - contribution to margin by premaxillae: $0=$ absent; $1=$ present.

8. Nasal bone as single consolidated ossification: $0=$ absent - multiple bones carry supraorbital canal; $1=$ present.

9. Pineal foramen: $0=$ present; $1=$ absent.

10. Parietals (=sarcopterygian postparietal) - shape: $0=$ rectangular - long axis parallel to midline; $1=$ subquadrate/ square.

11. Frontals (=sarcopterygian parietals) - relative size: $0=$ frontal shorter than parietal; $1=$ frontal roughly equal to parietal; $2=$ frontal longer than parietal.

12. Intertemporal - relative length: $0=$ shorter than supratemporal; $1=$ of similar length to supratemporal; $2=$ of greater length than supratemporal.

13. Intertemporal-contact with supratemporal anterior to that between frontal and parietal: $0=$ absent; $1=$ present.

14. Dermosphenotic - contact with frontals blocked by intertemporal or dermopterotic: $0=$ absent; $1=$ present.

15. Extrascapulae - number of paired examples: $0=$ one pair; $1=$ two pairs.

16. Lachrymal - anterior expansion: $0=$ absent; $1=$ present.

17. Jugal - notch in anterior margin: $0=$ absent; $1=$ present .

18. Suborbital bones - anamestic bones between jugal and preoperculum: $0=$ absent; $1=$ present.

19. Accessory operculum: $0=$ absent; $1=$ present. 
20. Lateral gulars*: $0=$ large with rounded posterolateral profile; $1=$ equivalent in area to three branchiostegal rays, angular posterolateral profile; $2=$ of similar size and shape to adjacent branchiostegal rays.

21. Mandibular canal-course of canal: $0=$ traces ventral margin of jaw along entire length; $1=$ arches dorsally in anterior half of jaw.

22. Dentary with conspicuously reflexed distal tip: $0=$ present; $1=$ absent.

23. Infradentaries - number of*: $0=$ more than two; $1=$ two (angular and surangular); $2=$ one (angular only).

24. Enlarged parasymphysial teeth: $0=$ present; $1=$ absent.

25. Acrodin caps on teeth: $0=$ absent; $1=$ present.

26. Porous ganoine ornamentation on lower jaw: $0=$ absent; $1=$ present.

27. Mentomeckelian region ossified: $0=$ present; $1=$ absent.

28. Parasphenoid - ascending processes: $0=$ absent; $1=$ present.

29. Parasphenoid - anterior tripartite subdivision: $0=$ absent; $1=$ present.

30. Ganoine: $0=$ present; $1=$ absent. Source: Zhu et al. 2009, character 149. Ganoine sensu stricto defined as a single or multi-layered enamel covering with variable surface (tuberculated or smooth, with or without pores).

31. Scale rows, number of: $0=$ fewer than $60 ; 1=$ more than 60 .

32. Scales - Peg-and-socket articulation between scales with narrow based peg: $0=$ present; $1=$ absent.

33. Scales - anterodorsal extension: $0=$ present; $1=$ absent.

34. Scales: $0=$ macromeric; $1=$ micromeric.

35. Scales - well-developed pores/punctae on ganoine surface: $0=$ absent; $1=$ present.

36. Scales - curved ridges coursing along anterior margin of scale, truncating transverse ornament ridges: $0=$ absent; $1=$ present .

37. Fringing fulcra: $0=$ absent; $1=$ present. Note: coding simplified to simple presence or absence. The structures previously coded as "unpaired, modified lepidotrichs" for Cheirolepis spp. in Friedman \& Blom (2006) and Long et al. (2008) have been demonstrated to be true paired fulcra by Arratia (2009).

38. Pelvic fins: $0=$ present; $1=$ absent or greatly reduced.

39. Presupracleithrum: $0=$ absent; $1=$ present.

40. Scapulacoracoid with horizontal plate: $0=$ absent; $1=$ present.

41. Pectoral fin-anterior rays embrace protopterygium: $0=$ absent; $1=$ present .

42. Pectoral fin - metapterygium enlarged relative to radials: $0=$ absent; $1=$ present.

43. Pectoral fin insertion: $0=$ into basal fleshy lobe; $1=$ directly into lateral flank.

44. Pectoral fin segmentation: $0=$ roughly even segmentation to fin-base; $1=$ proximal segments elongated with terminal segmentation; $2=$ no significant segmentation on pectoral fin. Note: as described in Choo (2009), the pectoral fin of Howqualepis has terminal segmentation.

45. Pelvic fin insertion: $0=$ short based; $1=$ long based.

46. Caudal fin - epichordal lobe: $0=$ present; $1=$ absent.

47. Fulcra on median dorsal surface of caudal fin: $0=$ present; $1=$ absent.

48. Scutes anterior to dorsal fin: $0=\mathrm{few}-$ limited to region anterior to dorsal fin; $1=$ complete series from occiput to dorsal fin; $2=$ no median dorsal scutes anterior to dorsal fin.

49. Ventral scutes between caudal and anal fins: $0=$ present; $1=$ absent

50. Ventral scutes anterior to anal fin: $0=$ present; $1=$ absent.
51. Anal fin - relative position to ( 2 nd) dorsal fin*: $0=$ shifted anterior to dorsal fin; $1=$ opposite to dorsal fin; $2=$ shifted posterior to dorsal fin.

52. Dorsal fins, number of: $0=$ two; $1=$ one.

53. Dermohyal: $0=$ absent; $1=$ present.

54. Dermosphenotic*: $0=$ absent; $1=$ present - with distinct posterior ramus; $2=$ present - without distinct posterior ramus. Note: as in Long et al. 2008, character 54.

55. Intertemporal - contact with parietal: $0=$ no contact; $1=$ contacts parietal laterally; $2=$ contacts parietal posterolaterally. Source: Cloutier \& Arratia (2004), character 58.

56. Rostral - shape of: $0=$ widens anteriorly; $1=$ equal anteriorly and posteriorly; $2=$ narrows anteriorly. Source: Cloutier \& Arratia (2004), character 39.

57. Nasal-mesial margin notched for anterior nostril: $0=$ absent; 1=present. Source: Cloutier \& Arratia (2004), character 44.

58. Quadratojugal as distinct ossification: $0=$ present; $1=$ absent. Source: Cloutier \& Arratia (2004), character 92.

59. Antorbital bone: $0=$ absent; $1=$ present. Source: Cloutier \& Arratia (2004), character 78.

60. Suborbital bones contributing to dorsal margin of orbit: $0=$ absent; $1=$ present.

61. Infraorbitals - number of: $0=$ two; $1=$ more than two. Source: Cloutier \& Arratia (2004), character 83.

62. Jugal canal: $0=$ absent; $1=$ present.

63. Maxilla - posteroventral overlap of lower jaw: $0=$ posteroventral maxilla largely straight with minimal overlap of the lower jaw: 1 =posteroventral extension of the maxilla with pronounced overlap of the lower jaw. Source: Cloutier \& Arratia (2004), character 19.

64. Dermopterotic: $0=$ absent; $1=$ present. Source: Cloutier \& Arratia (2004), character 70.

65. Preoperculum - vertical linear ornament: $0=$ absent; $1=$ present. Source: new character.

66. Serrated linear ganoine ornament on skull roof: $0=$ absent; $1=$ present. Source: new character, highlighting the distinctive 'herringbone' ornamentation found on Moythomasia spp. (Gardiner, 1984).

67. Operculum - relative size: $0=$ at least twice as high as suboperculum; $1=$ less than twice as high as suboperculum. Source: Cloutier \& Arratia (2004), character 109.

68. Suboperculum - narrow, tapering anterodorsal process: $0=$ absent; $1=$ present. Source: Long et al. (2008), character 67.

69. Supratemporal - narrow anterolateral flange forming ventral margin of spiracular opening: $0=$ absent; $1=$ present. Note: new character.

70. Extrascapulae-medially-directed branch of sensory canals: $0=$ present; $1=$ absent. Note: new character.

71. Median extrascapular: $0=$ present; $1=$ absent.

72. Branchiostegal rays -1 st ray ventral to suboperculum: $0=$ of similar depth to adjacent branchiostegal ray; $1=$ deeper than 2 nd branchiostegal ray. Source: Cloutier \& Arratia (2004), character 113.

73. Facet for parasymphysial tooth-whorl on anterior dentary: $0=$ present; $1=$ absent. Source: new character.

74. Mandibular canal: $0=$ primarily carried by infradentaries; 1 = primarily carried by dentary. Source: Zhu et al. (2009), character 120 (in part).

75. Dermal intracranial joint: $0=$ present; $1=$ absent. Source: Zhu et al. (2009), character 21.

76. Scales - anastomosing linear ornament: $0=$ absent; $1=$ present. Source: new character.

77. Maxilla-shape of anterior section: $0=$ straight; $1=$ reflexed. Source: new character. 


\subsection{Appendix 2: Data matrix}

OUTGROUP TAXA
Guiyu oneiros
Onychodus jandemarrai
Miguashaia bureaui
Osteolepis macrolepidotus
DEVONIAN INGROUP TAXA
Cheirolepis canadensis
Cheirolepis schultzei
Cheirolepis trailli
Cuneognathus gardineri
Donnrosenia schaefferi
Gogosardina coatesi
Howqualepis rostridens
Kentuckia hlavini
Krasnoyarichthys jesseni
Limnomis delaneyi
Mimipiscis bartrami
Mimipiscis toombsi
Moythoamsia sp. nov.
Moythomasia durgaringa
Moythomasia nitida
Osorioichthys marginis
Stegotrachelus finlayi
Tegeolepis clarki
CARBONIFEROUS INGROUP TAXA
Mansfieldiscus sweeti
Melanecta anneae
Novagonatodus kasantsevae
Wendichthys dicksoni
Woodichthys bearsdeni

\section{OUTGROUP TAXA}

Guiyu oneiros

Onychodus jandemarrai

Miguashaia bureaui

Osteolepis macrolepidotus

DEVONIAN INGROUP TAXA

Cheirolepis canadensis

Cheirolepis schultzei

Cheirolepis trailli

Cuneognathus gardineri

Donnrosenia schaefferi

Gogosardina coatesi

Howqualepis rostridens

Kentuckia hlavini

Krasnoyarichthys jesseni

Limnomis delaneyi

Mimipiscis bartrami

Mimipiscis toombsi

Moythoamsia sp. nov.

Moythomasia durgaringa

Moythomasia nitida

Osorioichthys marginis

Stegotrachelus finlayi

Tegeolepis clarki

CARBONIFEROUS INGROUP TAXA
Mansfieldiscus sweeti
Melanecta anneae
Novagonatodus kasantsevae
Wendichthys dicksoni
Woodichthys bearsdeni

\begin{tabular}{|c|c|}
\hline 0000000001 & 1111111112 \\
\hline 1234567890 & 1234567890 \\
\hline 0000000000 & $0---000000$ \\
\hline 0000000000 & $0---0 ? 0000$ \\
\hline 0000 ???010 & $0---010000$ \\
\hline 0000001000 & $0---010000$ \\
\hline ?0000100A0 & 1000001010 \\
\hline $000001 ? 010$ & 2??000101? \\
\hline 0000010000 & 1000001010 \\
\hline ??11110101 & $20100 ? 000 ?$ \\
\hline ?111010100 & 10100 ?? 011 \\
\hline 0001010100 & $1000 ? ? 0001$ \\
\hline 1011010101 & 2010010001 \\
\hline ??110??110 & $22010 ? 011 ?$ \\
\hline ? ? ? ? ? ? ? ? 1 & 200 ? 0 ? ? ? 1 ? \\
\hline 1011110101 & 2000000001 \\
\hline 0101010100 & 1000000001 \\
\hline 0111011100 & 1000000001 \\
\hline 0111010100 & 1100110001 \\
\hline 1111010101 & 2100110001 \\
\hline 0111010100 & 1100110111 \\
\hline 0011011110 & 1000100100 \\
\hline 0111010100 & 2001000011 \\
\hline 0011000110 & $1000 ? 1000 ?$ \\
\hline 0011010111 & $2--001011 ?$ \\
\hline 1011010111 & $2--0 ? 00 ? 0 ?$ \\
\hline 1011010101 & $2--00 ? 110 ?$ \\
\hline 0211010112 & 2011101101 \\
\hline 0011010111 & 2010100001 \\
\hline 4444444445 & 5555555556 \\
\hline 1234567890 & 1234567890 \\
\hline ??0000??100 & $2000-00100$ \\
\hline 0000000011 & $0000-001-1$ \\
\hline ? ? 00000011 & $1000-? 0001$ \\
\hline ?? 00000100 & $2000-00101$ \\
\hline $0 ? 00101100$ & $0111 \mathrm{~A} 00100$ \\
\hline ? ? ? ? ? ? ? ? ? & ??11?00100 \\
\hline 0000101110 & 0111100000 \\
\hline ? ?1?-11? 0 ? & 2111001000 \\
\hline ??111?1110 & $111101100 ?$ \\
\hline $11110 ? 1200$ & 2111211000 \\
\hline 1011101110 & 1111011000 \\
\hline ??1101111? & 2111101??1 \\
\hline ??101??202 & 211?2 ??1?? \\
\hline ??10-11200 & 2111201000 \\
\hline $11110 ? 1200$ & 2111111000 \\
\hline 1111011200 & 1111111000 \\
\hline 1110011200 & 2111201100 \\
\hline 1111011200 & 2111211000 \\
\hline ??10011200 & 1111201100 \\
\hline 1 ?00???1?? & ??11111000 \\
\hline ??10011200 & 1111201100 \\
\hline ??120??000 & 1102021101 \\
\hline ??11011110 & 2111-11010 \\
\hline ? ?1111111? & $21 ? 2-01100$ \\
\hline ??101??2 ?0 & $2111-21000$ \\
\hline ??10011110 & 2111001110 \\
\hline $1 ? 11011110$ & 2112011100 \\
\hline
\end{tabular}

\begin{tabular}{|c|c|}
\hline 2222222223 & 3333333334 \\
\hline 1234567890 & 1234567890 \\
\hline 0000000000 & 0000000000 \\
\hline $00000-0001$ & $0110-00000$ \\
\hline $01000-0001$ & 0110-0000? \\
\hline $00000-? 001$ & 0110-0000? \\
\hline $111000 ? 000$ & 1111001000 \\
\hline 11 ?000??? 0 & ?111001?0? \\
\hline $111000 ? 000$ & 1111001000 \\
\hline ?1?0 ? 0 ? ? ? & $011001111 ?$ \\
\hline 1110 ?0? ? ? 0 & $100010101 ?$ \\
\hline $01201000 ? 0$ & 1000001011 \\
\hline $0011 ? 01110$ & $100000101 ?$ \\
\hline ?100000?? & $000000101 ?$ \\
\hline ?? ?? ? ? ? ? 0 & $000000100 ?$ \\
\hline ?11010??? & $011001111 ?$ \\
\hline 0120100010 & 1000001011 \\
\hline 0120100010 & 1000001011 \\
\hline 111010 ??? 0 & 1000001011 \\
\hline 0110110110 & 0000101011 \\
\hline 1110 ?1??? 0 & $000010101 ?$ \\
\hline 1110 ? 0 ?? ? 0 & ?010001?1? \\
\hline ?110?01??0 & $000010101 ?$ \\
\hline $00 ? 1001100$ & 10010000 ?? \\
\hline 0110100 ?? 0 & 0010011011 \\
\hline ?1?01 ? ?? ? 0 & $1 ? ? 000100 ?$ \\
\hline 01 ? 0 ? 0 ?? ? 0 & $0 ? ? 000100 ?$ \\
\hline 01 ? 0 ? 0 ?? ? 0 & $0 ? ? 000100 ?$ \\
\hline $011010 ? 100$ & $000010100 ?$ \\
\hline 6666666667 & 777777 \\
\hline 1234567890 & 123456 \\
\hline 0000000000 & 000000 \\
\hline $0000-00000$ & 000000 \\
\hline $0-00-00000$ & ?1000- \\
\hline $0000-00000$ & 010000 \\
\hline 1000000001 & 011101 \\
\hline $10000000 ? 1$ & 011101 \\
\hline 1000000001 & 011101 \\
\hline ?1000000?1 & ?11100 \\
\hline ?100001001 & 011111 \\
\hline 1100011??1 & 011100 \\
\hline 1100001001 & 111111 \\
\hline ?100000??1 & ?11100 \\
\hline ?100010001 & $1 ? ? 10 ?$ \\
\hline ?1000010?1 & 011100 \\
\hline 1100011101 & 011110 \\
\hline 1100011101 & 011110 \\
\hline 1101101011 & 111100 \\
\hline 1100111011 & 111110 \\
\hline 1101110011 & 111110 \\
\hline 1000010001 & 111101 \\
\hline 1100000001 & 011100 \\
\hline $10000100 ? ?$ & 011101 \\
\hline 1110010001 & 011100 \\
\hline $11000100 ? ?$ & 011100 \\
\hline $11100100 ? 0$ & 011100 \\
\hline 1100000001 & 111100 \\
\hline 1100000001 & 011100 \\
\hline
\end{tabular}

\subsection{Appendix 3. Apomorphy list}

Unambiguous character states subtending branch nodes. Emboldened characters have a consistency index of one.
A: 6(0-1), 11(0-1), 22(0-1), 23(0-1), $31(0-1), 37(0-1), 52(0-1)$, 53(0-1), 54(0-1), 60(1-0), 62(0-1), 71(0-1), 74(0-1), 75(0-1), $77(0-1)$ 
A-Cheirolepis spp.: 17(0-1), 19(0-1), 34(0-1)

A-B: 3(0-1), 4(0-1), 8(0-1), 39(0-1), 41(0-1), 57(0-1), 67(0-1)

B-Osorioichthys: $7(0-1), 9(0-1), 15(0-1), 18(0-1), 58(1-0)$, $72(0-1)$

B-C: 20(0-1), 33(1-0), 43(0-1)

C-D: $16(0-1), 27(0-1), 51(2-1)$

D-Tegeolepis: 6(1-0), 9(0-1), 34(0-1), 37(1-0), 48(1-0), 53(1-

$0), 54(1-2), 61(0-1)$

D-Howqualepididae: 13(0-1), 45(0-1), 49(0-1), 58(1-0), 67(1$0), 68(0-1), 76(0-1)$

Howqualepididae-Donnrosenia: $\quad 2(0-1), \quad$ 19(0-1), 21(0-1), $35(0-1)$

Howqualepididae-Howqualepis: 10(0-1), 11(1-2), 72(0-1).

C-E: 25(0-1), 46(0-1), 48(1-2)

E-F: 29(0-1), 45(0-1)

F-Mimiidae: 23(1-2), 29(1-0), 44(0-1), 58(1-0)

Mimiidae-Gogosardina: no unambiguous inferred apomorphies

Mimiidae-Mimipiscis: 55(2-1), 76(0-1)

Mimipiscis-M. toombsi: 7(0-1), 51(2-1)

Mimipiscis-M. bartrami: no inferred apomorphies

F-G: 12(0-1), 16(0-1), 66(0-1), 70(0-1), 72(0-1)

G-Moythomasia sp. nov.: $67(1-0)$

G-H: 26(0-1), 31(1-0), 35(0-1), 76(0-1)

$\mathrm{H}-$ Moythomasia durgaringa: 1(0-1), 10(0-1), 11(1-2), 44(0-1), 58(1-0)

H-Moythomasia nitida: 18(0-1), 19(0-1), 51(2-1), 68(1-0)

E-I, 11(1-2), 19(0-1), 31(1-0)

I-Stegotrachelus: $14(0-1), 27(0-1), 51(2-1), 67(1-0)$

I-J: $10(0-1)$

$\mathrm{J}-\mathrm{K}: 45(0-1)$

K-Krasnoyarichthys: 50(0-2), 72(0-1)

K-L: 19 (1-0), 58(1-0)

L-Novogonatodus: 17(0-1), 56(0-2), 64(0-1), 71(1-0)

L-M: 5(0-1), 36(0-1), 38(0-1), 67(1-0)

M-Cuneognathus: $13(0-1), 55(2-0)$

M-Limnomis: $68(0-1)$

I-N: 9(0-1), 44(0-1), 48(2-1), 49(0-1)

$\mathrm{N}-$ Mansfieldiscus: $16(0-1), 33(0-1), 36(0-1), 56(0-1), 58(1-0)$, 64(0-1)

N-O: $67(1-0)$

O-Kentuckia: 12(0-2), 23(1-0), 26(1-0), 61(0-1)

O-P: 13(0-1), 15(0-1), 19(1-0), 39(1-0)

P-Wendichthys: $2,0-2,10,1-2,17(0-1), 44(1-0), 72(0-1)$

P-Q: 54(1-2)

Q-Melanecta: 1(0-1), 31(0-1), 45(0-1), 67(0-1)

Q-Woodichthys: 35(0-1), 66(0-1)

\subsection{Appendix 4. Literature sources used for scoring of taxa in the phylogenetic analysis}

\section{Taxon}

Guiyu oneiros

Onychodus jandemarrai

Miguashaia bureaui

Osteolepis macrolepido

Cheirolepis canadensis

Cheirolepis trailli

Cheirolepis schultzei

Cuneognathus gardineri

Donnrosenia schaefferi

Gogosardina coatesi

Howqualepis rostridens

Kentuckia hlavini

Krasnoyarichthys jesseni

Limnomis delaneyi

Mimipiscis bartrami

Mimipiscis toombsi

Moythomasia sp. nov.
Moythomasia durgaringa

Moythomasia nitida

Osorioichthys marginis

Stegotrachelus finlayi

Tegeolepis clarki

Mansfieldiscus sweeti

Melanecta anneae

Novagonatodus

kasantsevae

Wendichthys dicksoni

Woodichthys bearsdeni

Gardiner 1984; Choo in prep.

Jessen 1968; Jessen 1973; Choo in prep.

Taverne 1997

Swartz 2009; B. A. Swartz pers. comm. 2008

Dunkle \& Schaeffer 1973.

Long 1988

Coates 1998

Long 1988; Holland et al. 2007

Lund \& Poplin 1997

Coates 1998

\section{References}

Andrews, M., Long, J., Ahlberg, P., Barwick, R. \& Campbell, K. 2006. The structure of the sarcopterygian Onychodus jandemmarrai n. sp. from Gogo, Western Australia: with a functional interpretation of the skeleton. Transactions of the Royal Society of Edinburgh: Earth Sciences 96 (for 2005), 197-307.

Arratia, G. 2009. Identifying patterns of diversity of the actinopterygian fulcra. Acta Zoologica 90, 220-35.

Arratia, G. \& Cloutier, R. 1996. Reassesment of the morphology of Cheirolepis canadensis (Actinopterygii). In Schultze, H.-P. \& Cloutier, R. (eds) Devonian Fishes and Plants of Miguasha, Quebec, Canada, 165-97. München: Verlag Dr. Friedrich Pfeil.

Arratia, G. \& Cloutier, R. 2004. A new cheirolepidid fish from the Middle-Upper Devonian of Red Hill, Nevada, USA. In Arratia, G., Wilson, V. H. \& Cloutier, R. (eds) Recent Advances in the Origin and Early Radiation of Vertebrates, 583-98. München: Verlag Dr. Friedrich Pfeil.

Basden, A., Young, G. C., Coates, M. \& Ritchie, A. 2000. The most primitive osteichthyan braincase? Nature 403, 186-88.

Basden, A. M. \& Young, G. C. 2001. A primitive actinopterygian neurocranium from the Early Devonian of Southeastern Australia. Journal of Vertebrate Paleontology 21, 754-66.

Botella, H., Blom, H., Dorka, M., Ahlberg, P. E. \& Janvier, P. 2007. Jaws and teeth of the earliest bony fishes. Nature 448, 583-86.

Brazeau, M. D. 2009. The braincase and jaws of a Devonian 'acanthodian' and modern gnathostome origins. Nature 457, 305-08.

Choo, B. 2009. A basal actinopterygian fish from the Middle Devonian Bunga Beds of New South Wales, Australia. Proceedings of the Linnean Society of New South Wales 130, 37-46.

Choo, B., Long, J. A. \& Trinajstic, K. 2009. A new genus and species of basal actinopterygian fish from the Upper Devonian Gogo Formation of Western Australia. Acta Zoologica (Stockholm) 90 (Supplement 1), 194-210.

Cloutier, R. 1996. The primitive actinistian Miguashaia bureaui (Sarcopterygii). In Schultze, H.-P. \& Cloutier, R. (eds) Devonian Fishes and Plants of Miguasha, Quebec, Canada, 227-47. München: Verlag Dr. F. Pfeil.

Cloutier, R. \& Arratia, G. 2004. Early diversification of actinopterygians. In Arratia, G., Wilson, M. V. H. \& Cloutier, R. (eds) Recent Advances in the Origin and Radiation of Vertebrates, 217-70. München: Verlag Dr. Friedrich Pfeil.

Coates, M. I. 1998. Actinopterygians from the Namurian of Bearsden, Scotland, with comments on early actinopterygian neurocrania. Zoological Journal of the Linnean Society 122, 27-59.

Coates, M. I. 1999. Endocranial preservation of a Carboniferous actinopterygian from Lancashire, UK, and the interrelationships of primitive actinopterygians. Philosophical Transactions of the Royal Society, London, Series B 354, 435-62.

Cope, E. D. 1887. Geology and Palaeontology. American Naturalist, $1014-19$.

Daeschler, E. B. 2000. An early actinopterygian from the Catskill Formation (Late Devonian, Famennian) in Pennsylvania, U.S.A. Proceedings of the Academy of Natural Sciences of Philadelphia 150, 181-92.

Druce, E. C. 1975. Conodont biostratigraphy of the Upper Devonian reef complexes of the Canning Basin, Western Australia. Bureau of Mineral Resources, Australia, Bulletin 158.

Dunkle, D. H. 1964. Preliminary description of a palaeoniscoid fish from the Upper Devonian of Ohio, Scientific Publications of the Cleveland Museum of Natural History 3, 1-24.

Dunkle, D. H. \& Schaeffer, B. 1973. Tegeolepis clarki (Newberry), a palaeoniscoid from the Upper Devonian Ohio Shale. Palaeontographica Abteilung A 143, 151-58.

Esin, D. N. 1990. The scale cover of Amblypterina costata (Eichwald) and the Palaeoniscid taxonomy based on isolated scales. Paleontological Journal 2, 90-98. 
Evans, W. H. 1953. A catalogue of the American Hesperiidae indicating the classification and nomenclature adopted in the British Museum. Part III. Pyrginae Section 2. London: British Museum (Natural History).

Friedman, M. 2007. Styloichthys as the oldest coelacanth: implications for early osteichthyan interrelationships. Journal of Systematic Palaeontology 5, 289-343.

Friedman, M. \& Blom, H. 2006. A new actinopterygian from the Famennian of East Greenland and the interrelationships of Devonian ray-finned fishes. Journal of Paleontology 80, 1186-204.

Friedman, M. \& Brazeau, M. 2010. A reappraisal of the origin and basal radiation of the Osteichthyes. Journal of Vertebrate Paleontology 30, 36-56.

Gardiner, B. G. 1963. Certain palaeoniscoid fishes and the evolution of the snout in actinopterygians. Bulletin of the British Museum (Natural History): Geology 8, 254-325.

Gardiner, B. G. 1984. The relationships of the palaeoniscoid fishes, a review based on new specimens of Mimia and Moythomasia from the Upper Devonian of Western Australia. Bulletin of the British Museum (Natural History): Geology 37, 1-428.

Gardiner, B. G. 1993. Osteichthyes: Basal actinopterygians. In Benton, M. J. (ed.) The Fossil Record 2. London: Chapman and Hall.

Gardiner, B. G., Schaeffer, B. \& Masserie, J. A. 2005. A review of the lower actinopterygian phylogeny. Zoological Journal of the Linnean Society 144, 511-25.

Gardiner, B. G. \& Bartram, A. W. H. 1977. The homologies of ventral cranial fissures in osteichthyans. In Andrews, S. M., Miles, R. S. \& Walker, A. D. (eds) Problems in Vertebrate Evolution, 227-45. London: Academic Press.

Gardiner, B. G. \& Schaeffer, B. 1989. Interrelationships of lower actinopterygian fishes. Zoological Journal of the Linnean Society 97, $135-87$.

Gross W. 1950. Umbenennung von Aldingeria Gross (Palaeoniscidae; Oberdevon) in Moythomasia n. nom. Neues Jahrbuch für Geologie und Paläontologie, Monatshefte 1950, 145.

Holland, T. M., Long, J. A., Warren, A. \& Garvey, J. M. 2007. Second Specimen of the lower actinopterygian Novogonatodus Long 1988 from the Early Carboniferous of Victoria, Proceedings of the Royal Society of Victoria 18 (1), 1-10.

Huxley, T. H. 1880. On the applications of the laws of evolution to the arrangement of the Vertebrata and more particularly of the Mammalia. Proceedings of the Zoological Society of London 1880, 649-62.

Jarvik E. 1948. On the morphology and taxonomy of the Middle Devonian osteolepid fishes of Scotland. Kungliga Svenska Vetenskapsakpadamiens Hanglinger, Stockholm, Series 3 25, 1-301.

Jessen, H. 1968. Moythomasia nitida Gross und M. cf. striata Gross, Devonische palaeonisciden aus dem oberen Plattenkalk der Bergish-Gladbach-Paffrather Mulde (Rheinisches Schiefergebirge). Palaeontographica Abteilung A 128, 87-114.

Jessen, H. 1973. Weitere fischreste aus dem Oberen Plattenkalk der Bergisch-Gladbach Paffrather Mulde (Oberdevon Rheinisches Schiefergebirge). Palaeontographica A 143, 159-87.

Long, J. A. 1988. New palaeoniscoid fishes from the Late Devonian and Early Carboniferous of Victoria. Memoirs of the Association of Australasian Palaeontologists 7, 1-64.

Long, J. A. 2006. Swimming in Stone. The amazing Gogo fossils of the Kimberley. Perth: Fremantle Arts Centre Press.

Long, J. A., Choo, B. \& Young, G. 2008. A new basal actinopterygian fish from the Middle Devonian Aztec Siltstone of Antarctica. Antarctic Science 20, 393-412.

Long, J. A. \& Trinajstic, K. 2010. The Late Devonian Gogo Formation Lägerstatte of Western Australia: exceptional Early Vertebrate Preservation and Diversity. Annual Review of Earth and Planetary Sciences 38, 255-79.
Lund, R. 2000. The new actinopterygian order Guildayichthyiformes from the Lower Carboniferous of Montana (USA). Geodiversitas 22, 171-206

Lund, R. \& Poplin, C. 1997. The Rhadinichthyids (Paleoniscoid Actinopterygians) from the Bear Gulch Limestone of Montana (USA, Lower Carboniferous). Journal of Vertebrate Paleontology 17, 466-86.

Lund, R. \& Poplin, C. 2000. Cladistic Analysis of the Relationships of the Tarrasiids (Lower Carboniferous Actinopterygians). Journal of Vertebrate Paaleontology 22, 480-86.

Miles, R. S. 1971. The Holonematidae (placoderm fishes), a review based on new specimens of Holonema from the Upper Devonian of Western Australia. Philosophical Transactions of the Royal Society, London 263, 101-234.

Nicoll, R. S. 1977. Conodont apparatuses in an Upper Devonian palaeoniscoid fish from the Canning Basin, Western Australia. BMR Journal of Australian Geology and Geophysics 2, 217-28.

Patterson, C. 1982. Morphology and Interrelationships of Primitive Actinopterygian Fishes. American Zoologist 22, 241-59.

Pearson, D. M. \& Westoll, T. S. 1979. The Devonian actinopterygian Cheirolepis Agassiz. Transactions of the Royal Society of Edinburgh: Earth Sciences 70, 337-99.

Playford, P. E. \& Lowry D. C. 1966. Devonian Reef Complexes of the Canning Basin, Western Australia. Perth, Geological Survey of Western Australia 118, 74-76.

Poplin, C. M. \& Lund, R. 2002. Two Carboniferous fine-eyed palaeoniscoids (Pisces, Actinopterygii) from Bear Gulch (USA). Journal of Palaeontology 76, 1014-28.

Prokofiev, A. M. 2002. First finding of an articulated actinopterygian skeleton from the Upper Devonian of Siberia and a reappraisal of the family Moythomasiidae Kazantseva, 1971 (Osteichthyes). Palaeontological Research 6 (3), 321-27.

Schultze, H.-P. 1968. Palaeoniscoidea-Schuppen aus dem Australiens und Kanadas und aus dem mitteldevon Spitzbergens. Bulletin of the British Museum of Natural History (Geology) 16 (7), 343-68.

Schultze, H.-P. 1992. Early Devonian actinopterygians (Osteichthyes, Pisces) from Siberia. In Mark-Kurik, E. (ed.) Fossil Fishes as Living Animals, 233-42. Tallin: Academy of Sciences of Estonia.

Schultze, H.-P. \& Cumbaa, S. L. 2001. Dialipina and the characters of basal actinopterygians. In Ahlberg, P. E. (ed.) Major Events in Early Vertebrate Evolution, Systematics Association Special Volume Series 61, 315-32. London and New York: Taylor \& Francis.

Swartz, B. A. 2009. Devonian actinopterygian phylogeny and evolution based on a redescription of Stegotrachelus. Zoological Journal of the Linnean Society 156 (4), 750-84.

Taverne, L. 1997. Osorioichthys marginis, 'Palaéonisciforme' du famennien de Belgique, et la phylogénie de Actinoptérygiens dévonians (Pisces). Bulletin de l'institute Royal des Sciences Naturelles de Belgique 67, 57-78.

Teichert, C. 1949. Stratigraphy and palaeontology of Devonian portion of the Kimberley division, Western Australia. Australian Bureau of Mineral Resources Report 2, 1-55.

Toombs, H. A. \& Rixon, A. E. 1950. The use of plastics in the transfer method of preparing fossils. Museum Journal 50, 1-507.

Towner, R. R. \& Gibson, D. L. 1983. Geology of the onshore Canning Basin, Western Australia. Bureau of Mineral Resources, Australia, Bulletin 215.

Trinajstic, K. 1999a. Scale morphology of the Late Devonian palaeoniscoid Moythomasia durgaringa Gardiner \& Bartram, 1977. Alcheringa 23, 9-19.

Trinajstic, K. 1999b. Palaeoniscoid scales from the Late Devonian of Western Australia. Records of the Western Australian Museum 57, 93-106.

Zhu, M., Zhao W., Jia, L., Lu, J. \& Qiao, T. 2009. The oldest articulated osteichthyan reveals mosaic gnathostome characters. Nature 458, 469-74.

Original MS received 12 September 2008. Resubmitted MS received 11 February 2011. Accepted for publication 27 July 2011. 